\title{
Biocontrol of Bacterial Leaf Blight of Rice and Profiling of Secondary Metabolites Produced by Rhizospheric Pseudomonas aeruginosa BRp3
}

\author{
Sumera Yasmin ${ }^{1 *}$, Fauzia Y. Hafeez ${ }^{1,2}$, Muhammad S. Mirza ${ }^{1}$, Maria Rasul ${ }^{1}$, \\ Hafiz M. I. Arshad ${ }^{3}$, Muhammad Zubair ${ }^{1}$ and Mazhar Iqbal ${ }^{1 *}$
}

${ }^{1}$ Soil and Environmental Biotechnology Division, National Institute for Biotechnology and Genetic Engineering, Faisalabad, Pakistan, ${ }^{2}$ Department of Biosciences, COMSATS Institute of Information Technology, Islamabad, Pakistan, ${ }^{3}$ Plant Protection Division, Nuclear Institute of Agriculture and Biology, Faisalabad, Pakistan

OPEN ACCESS

Edited by:

Corné M. J. Pieterse

Utrecht University, Netherlands

Reviewed by:

Aziz Aziz,

University of Reims

Champagne-Ardenne, France

Tony Reglinski,

Plant \& Food Research, New Zealand

*Correspondence:

Sumera Yasmin

sumeraimran2012@gmail.com

Mazhar labal

hamzamgondal@gmail.com

Specialty section:

This article was submitted to

Plant Microbe Interactions,

a section of the journal

Frontiers in Microbiology

Received: 15 June 2017 Accepted: 15 September 2017 Published: 26 September 2017

Citation:

Yasmin S, Hafeez FY, Mirza MS Rasul M, Arshad HMI, Zubair M and labal M (2017) Biocontrol of Bacterial

Leaf Blight of Rice and Profiling of Secondary Metabolites Produced by

Rhizospheric Pseudomonas aeruginosa BRp3.

Front. Microbiol. 8:1895.

doi: 10.3389/fmicb.2017.01895
Xanthomonas oryzae pv. oryzae (Xoo) is widely prevalent and causes Bacterial Leaf Blight (BLB) in Basmati rice grown in different areas of Pakistan. There is a need to use environmentally safe approaches to overcome the loss of grain yield in rice due to this disease. The present study aimed to develop inocula, based on native antagonistic bacteria for biocontrol of BLB and to increase the yield of Super Basmati rice variety. Out of 512 bacteria isolated from the rice rhizosphere and screened for plant growth promoting determinants, the isolate BRp3 was found to be the best as it solubilized $97 \mu \mathrm{g} / \mathrm{mL}$ phosphorus, produced $30 \mu \mathrm{g} / \mathrm{mL}$ phytohormone indole acetic acid and $15 \mathrm{mg} / \mathrm{L}$ siderophores in vitro. The isolate BRp3 was found to be a Pseudomonas aeruginosa based on 16S rRNA gene sequencing (accession no. HQ840693). This bacterium showed antagonism in vitro against different phytopathogens including Xoo and Fusarium spp. Strain BRp3 showed consistent pathogen suppression of different strains of BLB pathogen in rice. Mass spectrometric analysis detected the production of siderophores (1-hydroxy-phenazine, pyocyanin, and pyochellin), rhamnolipids and a series of already characterized 4-hydroxy-2-alkylquinolines (HAQs) as well as novel 2,3,4-trihydroxy-2-alkylquinolines and 1,2,3,4-tetrahydroxy-2-alkylquinolines in crude extract of BRp3. These secondary metabolites might be responsible for the profound antibacterial activity of BRp3 against Xoo pathogen. Another contributing factor toward the suppression of the pathogen was the induction of defense related enzymes in the rice plant by the inoculated strain BRp3. When used as an inoculant in a field trial, this strain enhanced the grain and straw yields by 51 and 55\%, respectively, over non-inoculated control. Confocal Laser Scanning Microscopy (CLSM) used in combination with immunofluorescence marker confirmed $P$. aeruginosa BRp3 in the rice rhizosphere under sterilized as well as field conditions. The results provide evidence that novel secondary metabolites produced by BRp3 may contribute to its activity as a biological control agent against Xoo and its potential to promote the growth and yield of Super Basmati rice.

Keywords: Xanthomonas oryzae, super basmati, mass spectroscopy, HAQ, CLSM, BLB 


\section{INTRODUCTION}

Rice is an important staple food crop. The global production of rice paddy was 746.9 million tons and 496 million tons milled rice (http://www.fao.org/economic/est/publications/ rice-publications/rice-market-monitor- $\mathrm{rmm} / \mathrm{en} /$ ). The crop is widespread all over the world due to its wider adaptability under different environmental conditions. For this reason, Food and Agriculture Organization (FAO) regarded it as a strategic crop for food security in the world (Montano et al., 2014). Rice is used as a staple food in different areas of world especially in Asia (http:// www.britannica.com/plant/rice). In Pakistan, beside wheat, rice is the 2nd major cereal crop, which is widely cultivated, consumed, and exported. Among various cultivated varieties, Super Basmati rice variety is the most sought variety, as it is very popular among consumers, farmers, traders, and exporters due to its high quality grain and aroma (http://reap.com.pk/ news/news_detail.asp? newsid=3905). However, susceptibility of this variety to different diseases is a major problem. Among these, Xanthomonas oryzae pv. oryzae, the causal agent of bacterial leaf blight (BLB) is considered to cause severe yield losses (Arshad et al., 2015). This disease is widely prevalent among various rice varieties worldwide (Singh et al., 2015). Historically, BLB was initially reported in Japan during 1884-1885 and then reported in other rice growing countries (Gnanamanickam, 2009). Rice crop was severely affected by this disease in areas of tropica and Asia with heavy rainfall in monsoon. Initially, its occurrence in Pakistan was reported by Mew and Majid (1977) and Arshad et al. (2015). Later studies indicated an alarming increase in BLB incidence in Basmati rice growing areas of the country (Shah et al., 2009).

BLB occurs at different growth stages of rice and is manifested by either leaf blight or "Kresek" (acute wilting of young plants) symptoms. Xoo invades the plant through wounds or water pores. Lesions with wavy margins start from the tip of the leaf as the water pores are located at the margins of upper parts of the leaf. These water soaked lesions enlarge in size, turn yellow and ultimately lead to the death of plant (Nino-Liu et al., 2006).

In the past, various disease management strategies have been employed to reduce the yield losses and to avoid disease epidemics but use of chemicals has not been successful due to variation in sensitivity of pathogenic races toward applied chemicals. Development of mutation in pathogenic races is a major hindrance in developing a durable control (George et al., 1997). Moreover, due to toxic residues, usage of antibiotics and chemicals against rice BLB, has limitations (MacManus et al., 2002). Although, the use of host resistance genes seems to be practicable, single gene (Xa4) based breeding for BLB management has been shown to be ineffective due to evolution of sub-populations that overcome these resistance genes (Shanti et al., 2010). As a result, biological control seems to be a cost effective and environmentally friendly way to manage this serious threat (Gnanamanickam, 2009).

Most of the rhizospheric antagonistic bacteria such as Pseudomonas spp. can indirectly increase plant resistance by improving the plant growth. Responses of the host plant are due to root colonization of a plant by antagonistic rhizobacteria that play an important role in disease suppression. Lysobacter antibioticus have been documented as biocontrol agents against Xoo due to their rapid growth, easy application and effective leaf colonization (Ji et al., 2008). Plant growth promoting Bacillus spp. were found to suppress BLB in rice under greenhouse conditions (Chithrashree et al., 2011). Li et al. (2011) reported Streptomyces globisporus for the suppression of rice blast caused by Magnaporthe oryzae. The incidence of sheath blight was reduced by some biofilm forming and surfactant producing strains of Bacillus subtilis (Mousivand et al., 2012). Streptomyces philanthi and a commercial formulation of B. subtilis were found to be biologically active against rice sheath blight when integrated with chemical fungicides (Boukaew et al., 2013). Hydrogen cyanide (HCN) producing Pseudomonas chlororaphis significantly inhibited the growth of $M$. oryzae, showing its biocontrol properties against the causal agent of rice blast (Spence et al., 2014).

These antagonistic bacteria can directly suppress plant pathogens by producing antibiotics, enzymes like chitinases, glucanases, proteases, and siderophores or indirect mechanisms in which the antagonistic bacteria compete with the pathogen for a niche or nutrient sites (Bardin et al., 2015). These bacteria have been reported to reduce the disease incidence significantly under controlled as well as under natural field conditions. Bacillus and Pseudomonas spp. control the diseases caused by rice pathogens i.e., X. oryzae pv. oryzae, Rhizoctonia solani, and M. oryzae up to $90 \%$ depending on the bacteria used, pathogen and the rice variety (Montano et al., 2014). Induced systemic resistance (ISR) is an environmentally attractive option for disease control whereby plant defenses are enhanced as a result of their interaction with certain rhizobacteria. ISR contributes positively toward the biological control of plant pathogens and the defense related enzymes induced by the inoculated bacteria protect the host plants (Chithrashree et al., 2011). Systemic resistance was induced by Serratia sp. causing resistance against necrotrophic leaf pathogens in rice (Vleesschauwer et al., 2009).

However, most of the previous studies investigated either plant growth promoting activities or biocontrol activities of the bacterial isolates, exclusively. Previously, Kumar et al. (2005) and Fang et al. (2013) reported broad spectrum antifungal and biofertilizer activity of Pseudomonas aeroginosa and Pseudomonas aurantiaca. Similarly, different endophytic strains of $B$. subtilis have been reported to have plant growth promoting activity on cacao and biocontrol activity against phytopathogens like Moniliophthora perniciosa and Colletotrichum spp. but the antifungal metabolites were not investigated (Kumar et al., 2012; Nain et al., 2012; Falcao et al., 2014). The use of Pseudomonas and Bacillus strains have been reported for the biocontrol of rice pathogens such as Xoo, M. oryzae, and R. solani (Ji et al., 2008; Helene et al., 2011; Spence et al., 2014). However, again the major emphasis of these previous studies was on the biocontrol activity. Rhizospheric antagonistic Pseudomonas aeruginosa have been documented as beneficial biocontrol agents against Xoo (Yasmin et al., 2016) but the role of diverse secondary metabolites produced by different strains of $P$. aeruginosa in the suppression of BLB pathogen has not been reported earlier. 
Members of the Pseudomonas spp., including pathogenic as well as non-pathogenic strains, are capable of producing various extracellular secondary metabolites. These metabolites exhibit diverse properties i.e., function as virulence factors, siderophores (having high-affinity of iron ions), biosurfactants, and antimicrobial agents as well as in cell-to-cell signaling etc. These metabolites enable Pseudomonas spp. to adapt in different environments, colonize different hosts and compete with other species. Pseudomonas metabolites constitute chemical entities such as $\mathrm{N}$-acylhomoserine lactone (Cataldi et al., 2009), phenazine (Price-Whelan et al., 2006; Kumar et al., 2011; Jain and Pandey, 2016), pyochellin (Youard et al., 2007; Jayaseelan et al., 2014), phloroglucinol (Kidarsa et al., 2011), lahorenoic acid, diketopiperazines (Mehnaz et al., 2013), 4hydroxy-2-alkylquinolines (Lepine et al., 2004), rhamnolipids (Soberon-Chavez et al., 2005; Grosso-Becerra et al., 2016), and cyclic lipopeptides (Mehnaz et al., 2013). Knowing the chemistries of these metabolites can help with characterization of their biological and physiological activities. However, most of the existing studies have been confined to the analysis of individual metabolite class analysis and its biological properties (Kumar et al., 2005). There are few studies where more than one class of metabolites have been analyzed simultaneously. Even during the study of one physiological aspect like bacterial quorum-sensing, analysis of multiclass metabolites [N-acyl-L-homoserine lactone and 2-alkyl 4-(1H)quinolone] can enhance the scope of study (Ortori et al., 2011). In this study, detailed chemical characterization of the BRp3 supernatant has led to identification of a variety of previously known as well as novel metabolites of several chemical classes.

Despite the economic importance of BLB, complete resistance to this disease has not been reported. Furthermore, no local resistant varieties are commercially available in Pakistan. Therefore, to select bacteria with multiple beneficial applications for the improvement of rice crop, 512 rhizobacteria were isolated from different field sites of Punjab (Pakistan). After screening their plant growth promoting as well as biocontrol activities, the bacterium termed as BRp3, demonstrated the best results in rice yield improvement and biocontrol activity against the prevalent rice pathogen Xoo. This bacterium was subjected to detailed characterization of the secondary metabolites with ultimate aim to develop inocula of functionally well-characterized native antagonistic bacteria, having a "dualpurpose inoculum" with strong plant growth promoting and biocontrol aspects, for yield enhancement of "Super Basmati" rice variety.

Mass spectrometric analysis revealed the production of siderophores, rhamnolipids, a series of previously known and novel HAQs in the crude extract of BRp3. These results high-lighted the facts that $P$. aeroginosa BRp3, owing to its capability to produce a number of secondary metabolites in HAQ, rhamnolipids, and siderophores (phenazines and pyochellin) series, exhibited intense antimicrobial activity against Xoo pathogens. Hence, this bacterium could be used as an effective biocontrol agent against the rice pathogen Xoo.

\section{MATERIALS AND METHODS}

\section{Bacterial Pathogens Used}

Six X. oryzae pv. oryzae (Xoo) strains i.e., Xoo1, Xoo2, Xoo4, Xoo5, Xoo6, and Xoo7 were obtained from NIBGE Biotech Resource Centre (NBRC), Faisalabad (Yasmin et al., 2016). The pathogenicity of Xoo strains was tested by clip inoculation (Kauffman et al., 1973) on three susceptible rice varieties i.e., Super Basmati, Basmati 385, and Basmati 2000. Clip inoculation of Xoo1, Xoo2, Xoo4, Xoo5, and Xoo6 to rice showed typical symptoms of BLB on the inoculated leaves i.e., white to gray lesions starting from leaf tip to downward along leaf veins and margins. Bacterial Xoo pathogens were stored in PSA agar $(\mathrm{Ou}$, 1985) slants at $4^{\circ} \mathrm{C}$ and in $20 \%$ glycerol at $-80^{\circ} \mathrm{C}$ for further use.

\section{Isolation of Rhizobacteria with Biocontrol Activity}

Root samples of healthy rice plants in the vicinity of BLB infected plants were collected from fields of different rice growing sites. These root samples with adhering soil were used to isolate bacteria from rhizosphere, rhizoplane, and endosphere on Nutrient Agar (Norris and Ribbons, 1970), King's B (King et al., 1954), and Gould's S1 medium (Gould et al., 1985) using serial dilution method as mentioned by Somasegaran and Hoben (1994). Purified bacterial strains were stored in LB agar slants at $4^{\circ} \mathrm{C}$ and in $20 \%$ glycerol at $-80^{\circ} \mathrm{C}$.

The rhizobacteria were screened in vitro for inhibition of Xoo using plate diffusion method (Hewitt and Vincent, 1989). A fresh culture $(100 \mu \mathrm{L})$ of Xoo grown in PSA broth was spread onto LB plates. The liquid culture of bacterial strains grown in LB broth to be tested for antagonistic activity was spotted on LB plates already spread with Xoo strain. These plates were kept in incubator at 30 $\pm 2^{\circ} \mathrm{C}$ for $48 \mathrm{~h}$ and the antibiosis was observed by measuring the zone of inhibition of pathogen's growth (Velusamy et al., 2006).

Antagonistic activity of $P$. aeruginosa BRp3 was tested against phytopathogenic fungi like Fusarium oxysporum, Fusarium monoliforme, and Fusarium solani by dual culture assay on Potato Dextrose agar (PDA; Ji et al., 2008) and the percent inhibition was calculated (Yasmin et al., 2014).

\section{Primary Selection of Antagonistic Bacteria for Growth Promotion}

Primary selection of antagonist was carried out based on its antagonism as well as its effect on rice (Super Basmati) seedlings in a growth room experiment. The seeds were disinfected with sodium hypochlorite (1\%) for $5 \mathrm{~min}$ and then washed thrice with sterilized water. Twenty seeds soaked in overnight grown bacterial broth culture of antagonistic strain (log

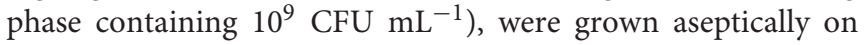
sterile wet filter paper each kept in each sterile Petri plate (14 cm diameter). Twenty-four bacteria were selected and there were three replicates for each treatment. Un-inoculated seedlings were used as control. The plates were kept in a growth room and maintained at a day/night temperature of $30 \pm 2^{\circ} \mathrm{C} / 25 \pm 2^{\circ} \mathrm{C}$ and $16 \mathrm{~h}$ day length with $20,000 \mathrm{Lux}$ light intensity. The plates were watered with sterilized distilled water in laminar flow. The number of germinated seedlings, 
radical length and hypocotyl length were measured after 10 days.

\section{Identification by $16 \mathrm{~S}$ rRNA Gene Sequencing and Phylogenetic Analysis}

CTAB method (Ausubel et al., 1992) was used to extract total genomic DNA of strain BRp3. Universal primers P1 and P6 were used to amplify 16S rRNA gene (Tan et al., 1997). QIAquick Gel Extraction Kit (QIAGEN Sciences, Maryland 20874, USA) was used to clean the amplified PCR product about $1.5 \mathrm{~Kb}$ of $16 S$ rRNA gene. Amplified PCR products were commercially sequenced by Macrogen, Inc. (Seoul, South Korea). Available sequences of bacterial lineage in NCBI were used to align and compare the sequence data using BLAST. Accession numbers were allocated after submitting the sequences to NCBI GenBank database (Yasmin et al., 2016).

For calculating phylogenetic tree of strain BRp3, closely related sequences were downloaded and aligned using CLUSTAL $\mathrm{X}$ and MacClade 4.05 (Thompson et al., 1997; Maddison and Maddison, 1999). Maximum Parsimony (MP), maximum likelihood (ML) and neighbor joining (NJ) methods were used for sequences analysis as mentioned by Mirza et al. (2009).

\section{Detection of Growth Promoting and Biocontrol Determinants}

Bacterial nitrogen fixation was estimated by using acetylene reduction assay (ARA; Hardy et al., 1968). Phosphate solubilization by the bacterium was measured on Pikovskaya agar medium added with insoluble tricalcium phosphate and quantified by Phospho-molybdate blue color method (Murphy and Riley, 1962). Quantification of produced Indole Acetic Acid (IAA) was carried out following the method of Tien et al. (1979). 1-Aminocyclopropane-1-carboxylic acid (ACC) deaminase activity was assessed in vials added with $3 \mu \mathrm{L}$ of ACC $(0.5 \mathrm{M})$ as a sole $\mathrm{N}$ source in $5 \mathrm{~mL}$ DF salt minimal medium (Penrose and Glick, 2003).

Production of siderophores was observed on universal chrome azurol "S" (CAS) agar medium (Schwyn and Neilands, 1987) and quantified as described by Rachid and Bensoltane (2005). Production of HCN was detected following the method as described by Lork (1948). Protease and chitinase activities were detected on skim milk agar (Denizci et al., 2004) and chitin agar (Brien and Colwall, 1987) media. Glucanolytic activity was detected on minimal medium supplemented with glucan source i.e., Lamimarin containing 0.5\% yeast extract (Qing et al., 2002). Starch hydrolyzing ability was detected on nutrient agar added with $2 \%$ starch (Marten et al., 2000). There were three biological replicates for all the tested growth promoting and biocontrol determinants.

Antibiotic resistance of the bacterial strain BRp3 was determined on antibiotic sensitivity sulfonamide (ASS) agar medium by disc diffusion method (Valverde et al., 2005) using commercial antibiotic susceptibility discs (Bioanalyse, Turkey; Imran et al., 2015).

\section{Mass Spectrometric Analysis of Culture Supernatant}

For the detection and identification of secondary metabolites, $P$. aeruginosa $\mathrm{BRp} 3$ was inoculated to $\mathrm{LB}$ medium $(500 \mathrm{~mL})$ and incubated with shaking at $30 \pm 2^{\circ} \mathrm{C}$ for 24 and $48 \mathrm{~h}$. To remove the bacterial cell pellet, the bacterial culture was centrifuged at $4^{\circ} \mathrm{C}$ for $15 \mathrm{~min}$ at $10,000 \mathrm{rpm} . \mathrm{pH}$ of the supernatant was reduced to 3.0 using $3 \mathrm{M} \mathrm{HCl}$ solution before its extraction with 500 $\mathrm{mL}$ ethyl acetate. This extraction step was repeated using 300 $\mathrm{mL}$ ethyl acetate. The combined organic layers were obtained and evaporated under reduced pressure by rotary evaporation. Residues were dissolved in $5 \mathrm{~mL}$ LCMS grade methanol and subjected to LCMS/MS analysis using mass spectrometer (LTQ XL Linear Ion Trap Mass Spectrophotometer, Thermo Scientific, USA), equipped with an ESI source. The samples were filter sterilized and were injected through direct syringe pump with a flow rate of $8 \mu \mathrm{L} \mathrm{min}^{-1}$. Samples were scanned at both positive and negative total ion full scan modes (mass scan range $\mathrm{m} / z 50$ 2,000 ) with source voltage and capillary voltage of $4.8 \mathrm{kV}$ and $23 \mathrm{~V}$, respectively. Capillary temperature and sheath glass flow $\left(\mathrm{N}_{2}\right)$ were $350^{\circ} \mathrm{C}$ and 30 arbitrary units, in both scan modes. The selected analytes were fragmented at positive and negative ion modes by employing collision induced dissociation (CID) energy of 35 (percentage of $5 \mathrm{~V}$ ) or otherwise stated.

The supernatant of the bacterial culture was studied for its antimicrobial activity against Xoo in plate diffusion assay at different time intervals $(24-144 \mathrm{~h})$ as described in section Isolation of Rhizobacteria with Biocontrol Activity. The supernatant of the bacterial culture with higher antimicrobial activity (after 24 and $48 \mathrm{~h}$ ) was further subjected to LCMS analysis for the detection of secondary metabolites.

\section{In Planta Evaluation for the Suppression of BLB}

Net House Experiment

Antagonistic bacteria BRp3 was evaluated in vivo for the suppression of BLB against reference strain Xoo2 (selected on the basis of its virulence) under natural light and temperature conditions at NIBGE net house during the rice growing season. The seeds were treated with the antagonistic bacteria $\left(10^{9}\right.$ CFU mL $\mathrm{mL}^{-1}$ ) for $2 \mathrm{~h}$ and sown in small plastic pots of $12 \times$ $7 \mathrm{~cm}^{2}$ diameter filled with $3 \mathrm{~kg}$ soil/ pot (texture clay loam, organic matter $0.4 \%, \mathrm{pH} 8.5$, EC $4.1 \mathrm{mS}$, viable cell count 1.8 $\times 10^{6}$ cell $\mathrm{g}^{-1}$ soil). The experiment was carried out using completely randomized block design (CRD). There were four replicates for each treatment with 15 plants per pot. After 21 days, the plants were given foliar spray treatment with their respective antagonistic bacteria $\left(10^{9} \mathrm{CFU} \mathrm{mL} \mathrm{m}^{-1}\right)$ made in sterilized distilled water. Control plants (healthy control) were sprayed with sterilized water. Antibiotic streptocyclin applied @ $5 \mathrm{mg} /$ pot was used as positive control. Sterilized water was used to clip inoculate the leaves of control plants whereas leaves of inoculated treatments and infected control (IC) were clip inoculated with broth culture of Xoo $\left(10^{6} \mathrm{CFU} \mathrm{mL}{ }^{-1}\right)$ on $23 \mathrm{rd}$ day of sowing as per the method of Kauffman et al. (1973). Lesion length was measured on 15th day of the inoculation and data for 
one treatment was obtained from 40 inoculated leaves. The plant dry weight obtained in the inoculated treatments was compared with the non-inoculated healthy control. Suppression of BLB was measured in terms of reduction in the mean bacterial blight lesion length on treated leaves compared to those of non-inoculated control using the following formula:

$\%$ Diseased leaf area (\%DLA) $=$

$$
\frac{\text { Total lesion length of the test sample }}{\text { Total leaf length of the test sample }} \times 100
$$

Antagonistic bacterium BRp3 was re-evaluated against another reference strain Xoo1 in large earthen pots of $24 \mathrm{~cm}$ diameter containing $10 \mathrm{~kg}$ soil with same characteristics as mentioned earlier in this section.

\section{Induction of Defense Related Enzymes}

Rice plants grown under net house condition, applied with foliar spray of BRp3 and clip inoculated with Xoo2 pathogen as described in section Net House Experiment, were also used to study the induction of defense related enzymes (Chithrashree et al., 2011).

Leaves were harvested at 24, 48, 72, and $144 \mathrm{~h}$ after application of foliar spray of strain BRp3 on rice plants. There were 15 plants per pot and five leaves were taken randomly from replicates of each treatment. These leaves were mixed thoroughly after cutting them and then $0.1 \mathrm{~g}$ sample was used immediately for analysis of different enzymes. Among different defense related enzymes, peroxidase (POD) activity was assayed using guaicol as a substrate at $470 \mathrm{~nm}$ wavelength (Hammerschmidt et al., 1982; Liang et al., 2011). Polyphenol oxidase (PPO) was determined at $280 \mathrm{~nm}$ using L-tyrosine as the substrate (Worthington, 1988). Decrease in the amount of hydrogen per oxide was determined at $240 \mathrm{~nm}$ wavelength to study the catalase (CAT) activity as described previously (Weisany et al., 2012). Phenylalanine ammonia-lyase (PAL) activity was analyzed at 290 $\mathrm{nm}$ wavelength by measuring the conversion of L-phenylalanine into trans-cinnamic acid (Benkeblia, 2000).

\section{Field Experiment}

Bacterial strain BRp3 was evaluated under field conditions against BLB using rice variety Super Basmati during crop season June-Oct 2013 in a BLB nursery at Plant Protection Division, NIAB, Faisalabad (a hot spot for BLB incidence). The soil sample was homogenized and used for further analysis $(\mathrm{pH} 8.2$, EC 1.8 $\mathrm{mS}, 1.3 \mathrm{mg}$ total $\mathrm{N} \mathrm{g}^{-1}$ soil, $1 \mu \mathrm{g}$ available $\mathrm{P} \mathrm{g}^{-1}$ soil, $0.03 \%$ organic matter and population density of indigenous bacteria

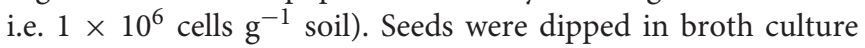

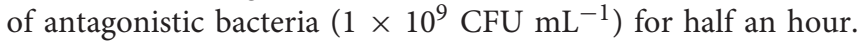
Inoculated/un-inoculated seeds were directly sown in seedbeds of $1 \mathrm{~m}$ row plots. Each bed was irrigated independently without allowing the water flow from one bed to irrigate another. The beds were separated by a distance of $0.5 \mathrm{~m}$ with mud bunds. Each treated row was bordered with a row as a buffer zone. Seeds treated with sterilized LB broth medium were considered as negative controls. Each treatment had three replicates arranged in a Randomized Complete Block Design (RCBD). Plant to plant distance was $22 \mathrm{~cm}$. Application of biocontrol agent and antibiotic i.e., streptocyclin $\left(500 \mathrm{~g} \mathrm{ha}^{-1}\right)$ was carried out as mentioned earlier for pot experiment. The leaves (60 leaves per treatment) were clip inoculated with Xoo7 at maximum tillering stage. Xoo7 was the prevalent strain isolated in the same season from BLB infected area of Sheikhupura, Pakistan. In addition to disease severity, straw weight, and grain weight were also recorded.

\section{Field Evaluation for Yield Increase of Rice}

Another field experiment was conducted during crop season June-Oct 2014 to compare the effects of BRp3 with that of commercial biofertilizer (BioPower) on the yield of rice variety Super Basmati with different levels of fertilization. The soil was collected from 10 sites of field $(0-200 \mathrm{~mm}$ depth) before sowing and after application of fertilizer. The soil sample were homogenized and used for further analysis i.e., $\mathrm{pH}$ (8.6), EC (4 mS), total $\mathrm{N}$ (2 $\mathrm{mg} \mathrm{g}^{-1}$ soil), available $\mathrm{P}\left(8 \mu \mathrm{g} \mathrm{g}^{-1}\right.$ soil), organic matter $(0.1 \%)$, and population density of indigenous bacteria $\left(1 \times 10^{6}\right.$ cells $\mathrm{g}^{-1}$ soil $)$ by viable cell count. At the time of transplanting, BioPower and the bacterial strain BRp3 were inoculated by root dip method (Tariq et al., 2007). Noninoculated treatments with recommended $\mathrm{N}$ and $\mathrm{P}(140-80 \mathrm{~kg}$ NP acre ${ }^{-1}$ ) and with $80 \%$ of the recommended $\mathrm{N}$ and $\mathrm{P}$ doses were considered as controls of experiment. Each treatment had four replicates in RCBD. Nutrient inputs of $\mathrm{N}$ and $\mathrm{P}$ were applied as urea and di-ammonium phosphate (DAP), respectively. Complete dose of DAP was applied before sowing and urea was applied in three split doses i.e., first one was added at the time of field preparation, second and third dose after 25 and 50 days of transplantation, respectively. The plot size was 4 $\times 7 \mathrm{~m}$. Planting distance and row spacing was $22 \mathrm{~cm}$. Plots were weeded by hand after water removal at each fertilizer application. The plants were harvested at maturity. Whole plot grain yield and straw yield was recorded after threshing. Plants were manually harvested and weighed after sun drying. Rice yield was expressed as weight of paddy at $14 \%$ water content (Wimberly, 1983).

\section{Rhizosphere Colonization Studies}

Viable count was used to monitor variations in the population of $P$. aeruginosa BRp3 associated with rice variety Super Basmati. The morphology of the colonies of the antagonistic strain was used as a monitoring tool as it produced green pigments in LB agar plates. The inoculated bacterium was further identified on the basis of its antibiotic resistance pattern, antagonism against Xoo strains, production of IAA and siderophores and P solubilization.

Three root and shoot samples from each replicate field plot were collected 14, 21, 40, and 60 days after treatment. Root and shoot samples were washed with sterile distilled water for few minutes. The shoot parts were crushed in sterilized phosphate buffer $(10 \mathrm{~mL})$. The suspension was used for preparing serial dilutions followed by plating on LB agar plates. Population level of strain was measured as $\log _{10} \mathrm{CFU} \mathrm{g} \mathrm{g}^{-1}$ fresh weight of roots and shoots.

Fluorescent antibodies (FA) against $P$. aeruginosa BRp3 were raised for colonization studies. Immunoglobins were separated 
and then conjugated with fluorescein isothiocynate (FITC). Unconjugated dye was separated with a Sephadex G-25 column chromatography following the method of Bilal et al. (1993). The quality and specificity of the FA was determined by staining a number of known cultures of $P$. aeruginosa (Somasegaran and Hoben, 1994).

In a pot experiment, surface sterilized seeds of rice variety Super Basmati were sown in small plastic pots having $50 \mathrm{~g}$ air-dried, sieved sterilized sand. The non-inoculated pots were treated independently as control. P. aeruginosa BRp3 was seed inoculated $\left(10^{9} \mathrm{CFU} \mathrm{mL} \mathrm{mL}^{-1}\right)$. All pots were kept in net house during rice growing season. Plants were harvested 21 days after seed germination. Nonspecific adsorption of stain was suppressed using RhITC conjugate. Specific FA was used to stain the roots (Yasmin et al., 2014). Confocal laser scanning microscope (Olympus FV1000, Japan) facilitated with an Argonion laser and FV10-ASW 1.7 imaging software was used to observe the fluorescent bacteria at 488 and $525 \mathrm{~nm}$ for absorption and emission of FITC, respectively.

\section{Statistical Analysis}

Data obtained from in vitro and in vivo seed/ plant inoculation experiments was subjected to Analysis of Variance (ANOVA). The treatment means were separated by Duncan's multiple range test (DMRT) for plate/pot experiments at $1 \%(P \leq 0.01)$ and field evaluation at $5 \%(P \leq 0.05)$ significance level, respectively using “MSTATC" program (Duncan, 1995).

\section{RESULTS}

\section{Isolation and Identification of Rhizobacteria with Biocontrol Activity}

Out of 512 bacterial isolates obtained from different host plants, 79 isolates showed antagonistic activity against Xoo (Tables $\mathrm{S} 1, \mathrm{~S} 2$ ). Isolate BRp3 showed maximum growth inhibition of all the tested Xoo strains with zone of inhibition ranged from 10 to $24 \mathrm{~mm}$ (Table 1). There were three replicates each time and the experiment was repeated thrice. On PDA medium, BRp3 also showed the inhibition of F. moniliforme and F. solani up to 43.3 and $75 \%$, respectively (Table S1).

$16 \mathrm{~S}$ rRNA gene sequencing identified the strain BRp3 as Pseudomonas sp. Results of Blast showed 99\% homology with 16S rRNA gene of $P$. aeruginosa isolate PM-007 (Accession no. KY908465.1). 16S rRNA gene sequence of selected strain was submitted to GenBank data base and accession number was allocated (HQ840693). 16S rRNA sequence based phylogenetic analysis showed that the bacterium BRp3 had maximum sequence similarity with $P$. aeruginosa. It occupied the same phylogenetic branch as the $P$. aeruginosa group (Figure S1).

\section{Primary Selection of Antagonistic Bacteria for Growth Promotion}

To study the effect of antagonistic bacteria on seedlings, rice seeds were pretreated with different bacteria. Antagonistic bacteria showed variable effects on germination of rice seeds, radical, and hypocotyl length (Figure S2). Bacterial isolates showing less effect 
on these growth parameters of the rice variety Super Basmati as compared to the control were excluded from the further study.

\section{Detection of Growth Promoting and Biocontrol Determinants}

The bacterial strain BRp3 produced $30 \pm 2 \mu \mathrm{g} \mathrm{mL}-1$ IAA when supplemented with tryptophan and solubilized P (97 \pm $4 \mu \mathrm{g} \mathrm{mL}^{-1}$ ) as quantified by spectrophotometer (Table 1). The bacterium did not show the nitrogenase activity but used ACC as carbon source in DF salt minimal medium. BRp3 produced volatile compounds such as $\mathrm{HCN}$ as observed by a color change of filter paper from yellow to brown in the plate assay. BRp3 showed the activity of proteases but did not produce chitinases and glucanases. This strain was able to hydrolyze starch and showed siderophores production on CAS blue agar medium with a color change from blue to orange. Quantification of siderophores using spectrophotometer showed the production of $15 \pm 1.5 \mathrm{mg} \mathrm{L}^{-1}$ siderophores by the strain BRp3 (Table 1; Figure S3).

The tests on antibiotic resistance showed that BRp3 was intrinsically resistant to 12 antibiotics i.e., Amikacin, Aztrreonum, Ampicillin, Carbenicillin, Cephradine, Chloramphenicol, Doxycycline, Erythromycin, Gentamicin, Neomycin, Nalidixic acid, and Streptomycin (Table S3).

\section{Mass Spectrometric Analysis of Culture Supernatant}

Filter sterilized cell free extract of $P$. aeruginosa BRp3 was studied by ESI-MS/MS technique. Samples were injected using direct syringe pump and analyzed at both positive as well as negative scan mode. At $24 \mathrm{~h}$ growth (after getting the bacteria from culture stock), analysis of crude extract demonstrated the presence of predominant metabolites such as 1-hydroxy-phenazine having $\mathrm{m} / z$ at $197[\mathrm{M}+\mathrm{H}]^{+}, 219[\mathrm{M}+\mathrm{Na}]^{+} ;$pyocyanin $\mathrm{m} / z$ at 211 $[\mathrm{M}+\mathrm{H}]^{+}, 233[\mathrm{M}+\mathrm{Na}]^{+}$and possibly lahorenoic acid at $\mathrm{m} / z$ $245[\mathrm{M}+\mathrm{H}]^{+}, 267[\mathrm{M}+\mathrm{Na}]^{+}$(Figure 1). However, this trend altered after the $48 \mathrm{~h}$ growth and prominent peaks of 4hydroxy-2-alkylquinolines (HAQs) exhibiting $\mathrm{m} / \mathrm{z}$ from 214 to

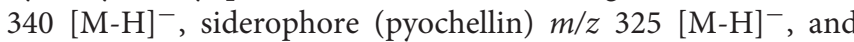
rhamnolipids $\mathrm{m} / \mathrm{z} 503,529,539,635,649[\mathrm{M}-\mathrm{H}]^{-}$(Figure 2). The presence of these metabolites was confirmed using tandem mass spectrometry as well as through comparing the values with the literature data (Table 2).

The bacterium demonstrated the capability to produce large variety of HAQs. Molecular ion peaks of $17 \mathrm{HAQs}$, representing seven analogous series, were identified (Table 2). These HAQs were classified into various groups on the basis of hydrogen, alkyl and hydroxyl groups at the two and three positions of heterocyclic ring, as well as $N$-oxide group at the position of quinoline nitrogen (Serial No. 1-7, Table 2). Serial No. 1 HAQs represent the eight analogs, having hydrogen at 3-position with $\mathrm{m} / z[\mathrm{M}+\mathrm{H}]^{+}$values $216,230,242,244,258,270,298$, and 326. These HAQs are relatively simpler 4-hydroxy-2-alkylquinolines, which only varied from each other on the basis of saturated or unsaturated alkyl side chain length. The molecular ions peaks $[\mathrm{M}+\mathrm{H}]^{+}$and $[\mathrm{M}-\mathrm{H}]^{-}$of these HAQs were further analyzed by collision induced dissociation (CID) and compared with literature data. In Serial No. 2 (Table 2), an HAQ having $\mathrm{m} / \mathrm{z}$ at $258[\mathrm{M}-\mathrm{H}]^{-}$, exhibited the highest peak intensity in full scan MS negative ion mode (Figure 3), representing a 3,4-dihydroxy2-heptylquinoline (HHAQ), in which hydrogen at 3-position is substituted with hydroxyl group (Deziel et al., 2004). The structure of this molecule has been thoroughly investigated through collision induced dissociation at positive and negative ion modes to unambiguously profile the fragmentation data. Assigning the three daughter peaks can confirm the structure of HHAQ (Table 2, Figure 3).

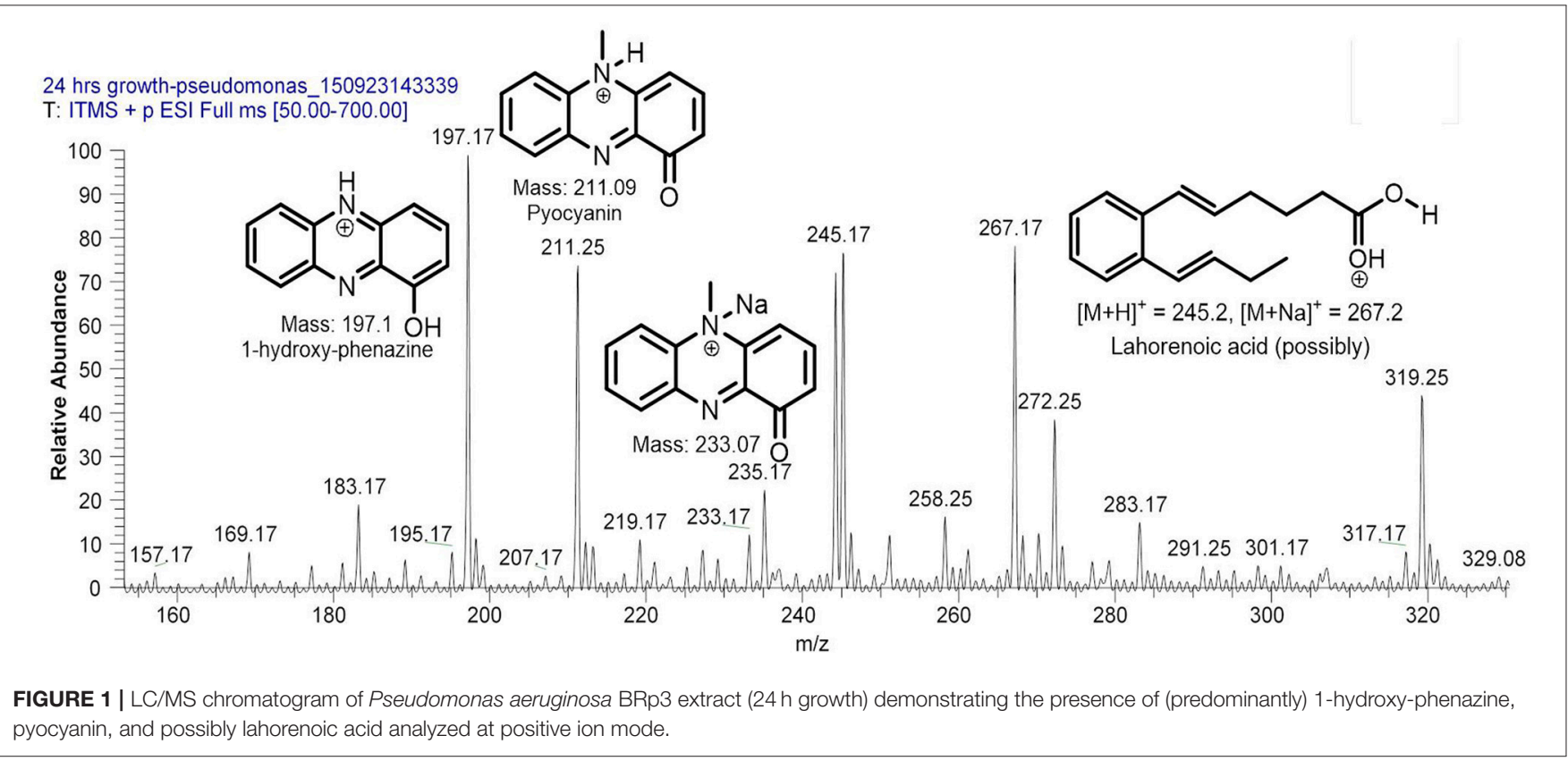




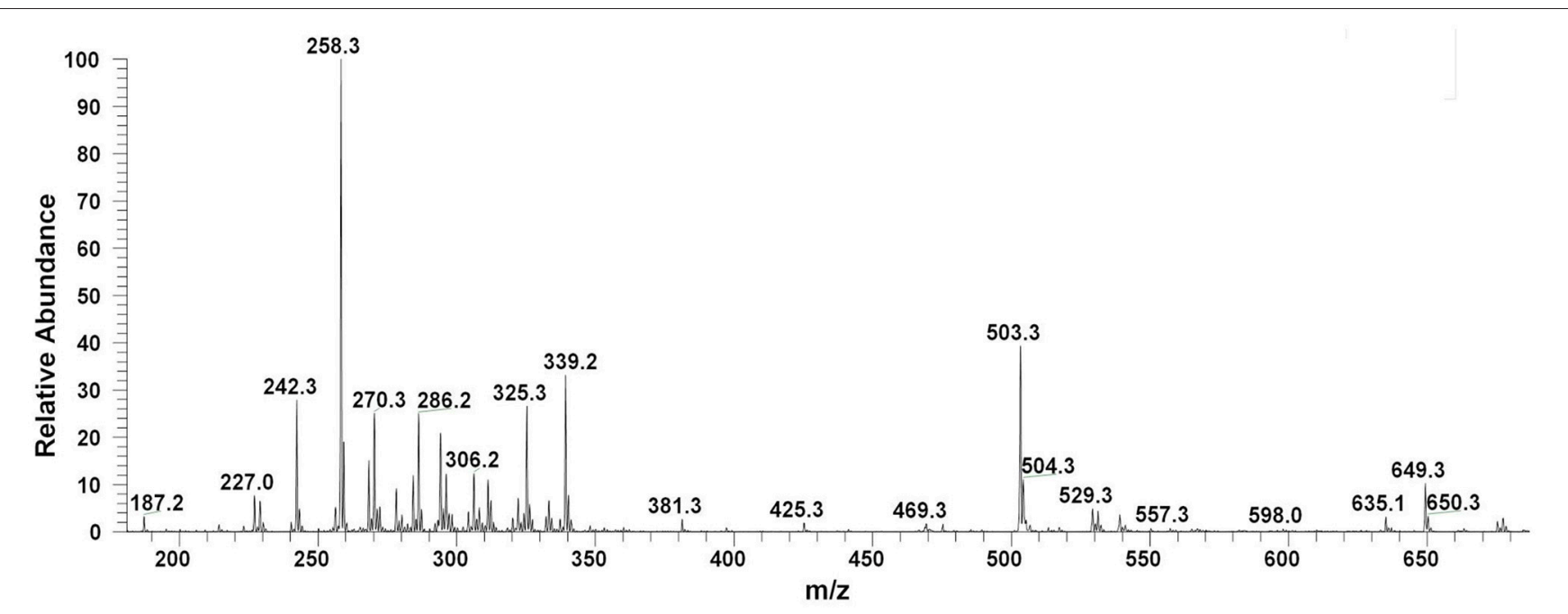

FIGURE 2 | LC/MS chromatograms of Pseudomonas extract (48 h growth) indicating the presence of 4-hydroxy-2-alkylquinolines (HAQs) molecular ions species, siderophore (pyochellin, $m / z$ 325), and rhamnolipids ( $m / z$ 500-650), at negative ion mode analysis.

HAQ representing $m / z$ at $270[\mathrm{M}+\mathrm{H}]^{+}$\& $268[\mathrm{M}-\mathrm{H}]^{-}$ (Table 2, Serial No. 3) exhibited the structure of 4-hydroxy-3methyl-2-alkylquinolines (HMAQ). Fragmentation of the parent peaks through CID produced the daughter ions, which correlated well with the proposed structure. Two analogs of 4-hydroxy3-methyl-2-alkylquinolines $\mathrm{N}$-oxide (HMAQ $\mathrm{N}$-oxide) $\mathrm{m} / \mathrm{z}$ at 286 and $288[\mathrm{M}+\mathrm{H}]^{+}$, were also spotted (Table 2, Serial No. 4), exhibiting octaene and octane side chains, respectively.

However, to our surprise, a poly-hydroxy HAQ analog having $\mathrm{m} / \mathrm{z}$ at $278[\mathrm{M}-\mathrm{H}]^{-}$, demonstrating an interesting putative structure of 2,3,4-trihydroxy-2-alkylquinoline (HHHAQ), was identified at negative ion mode (Table 2, Serial No. 5). On collision induced dissociation, this molecule spontaneously lost two moles of water, leaving a stable ion species at $m / z 242$ (4-hydroxy-2-alkylquinoline), which on further fragmentation yielded the expected daughter ions at $m / z$ values of 198,184 , 170, 158, 157, and 144 (Figure 4). This hydroxylation trend was further enhanced in Serial No. 6 compounds (Table 2), whose putative structures were assigned as 2,3,4-trihydroxy2-alkylquinolines $\mathrm{N}$-oxide (HHHAQ $N$-oxide). Two analogs in this tetrahydroxyl series were identified with $\mathrm{m} / z 294$ and $306[\mathrm{M}-\mathrm{H}]^{-}$, representing 2-heptyl and 2-octaenyl side chains, respectively. Collision induced dissociation of $\mathrm{m} / \mathrm{z} 294$ yielded the major daughter ion at $\mathrm{m} / z 258$ after losing 2 moles of $\mathrm{H}_{2} \mathrm{O}$ (Figure 5). The other fragmentation products having $m / z$ values of 196, 194, 183,170, 158, and 144 were also structurally assigned, which supported the putative structure of $\mathrm{m} / z$ 294. Similarly, collision induced dissociation of $\mathrm{m} / \mathrm{z} 306$ ion, produced a stable daughter ion at $\mathrm{m} / z 270$ after the loss of 2 moles of water, which on further fragmentation yielded daughter ions at $\mathrm{m} / z$ values of 252, 242, 181, 170, 158, 157, and 144 (Figure S4). Finally, 4-hydroxy-2-alkylquinoline $\mathrm{N}$-oxide (HAQ $\mathrm{N}$-oxide) representing $m / z$ at $340[\mathrm{M}-\mathrm{H}]^{-}$(Table 2, Serial No. 7) was detected. Fragmentation of $\mathrm{m} / z 340$ through CID demonstrated the daughter ions at $\mathrm{m} / z$ values of $322,312,297,291,277,260$,
$198,184,183,170$, and 144, which correlated with the expected fragments.

The supernatant of strain BRp3 harvested at different time intervals showed Xoo suppression in plate diffusion assay with an inhibition zone of $8-15 \mathrm{~mm}$. The maximum antibacterial activity against Xoo was observed for the supernatant harvested after 24-48 h growth of bacterial culture (Figure S7).

\section{In Planta Evaluation for the Suppression of BLB}

Net House Experiment

The bacterial strain BRp3 was studied for in vivo suppression of BLB in a pot experiment under net house conditions. Bacterial inoculation resulted in significant disease suppression shown by percent diseased leaf area (3.7\% DLA) compared to that of the infected control (37.2\%) against Xoo. Besides reducing the disease incidence, strain BRp3 improved the plant dry weight as compared to control plants without inoculation.

Another experiment conducted in large earthen pots showed that the effect of strain was statistically significant for disease suppression and growth promotion compared to infected and healthy control plants. DLA (\%) of plants inoculated with BRp3 was $4.7 \%$ as compared to infected $(23.3 \%)$ and streptocyclin treated plants (7.1\%; Figure 6).

\section{Induction of Defense Related Enzymes}

The net house experiment to study the accumulation of defense related enzymes showed that upon Xoo clip inoculation of rice plants inoculated with $P$. aeruginosa strain BRp3, higher activities of defense related enzymes were observed at 24 and $48 \mathrm{~h}$ post-inoculation. Peroxidase was observed to be maximum as compared to healthy and infected control after $24 \mathrm{~h}$ of Xoo inoculation. The higher activity of Catalase was observed after $48 \mathrm{~h}$ of Xoo inoculation. The inoculation of BRp3 resulted in higher induction of Poly Phenol Oxidase (PPO) activity at 24, 
TABLE 2 | Metabolites produced by Pseudomonas aeruginosa BRp3 detected by ESI-MS/MS.

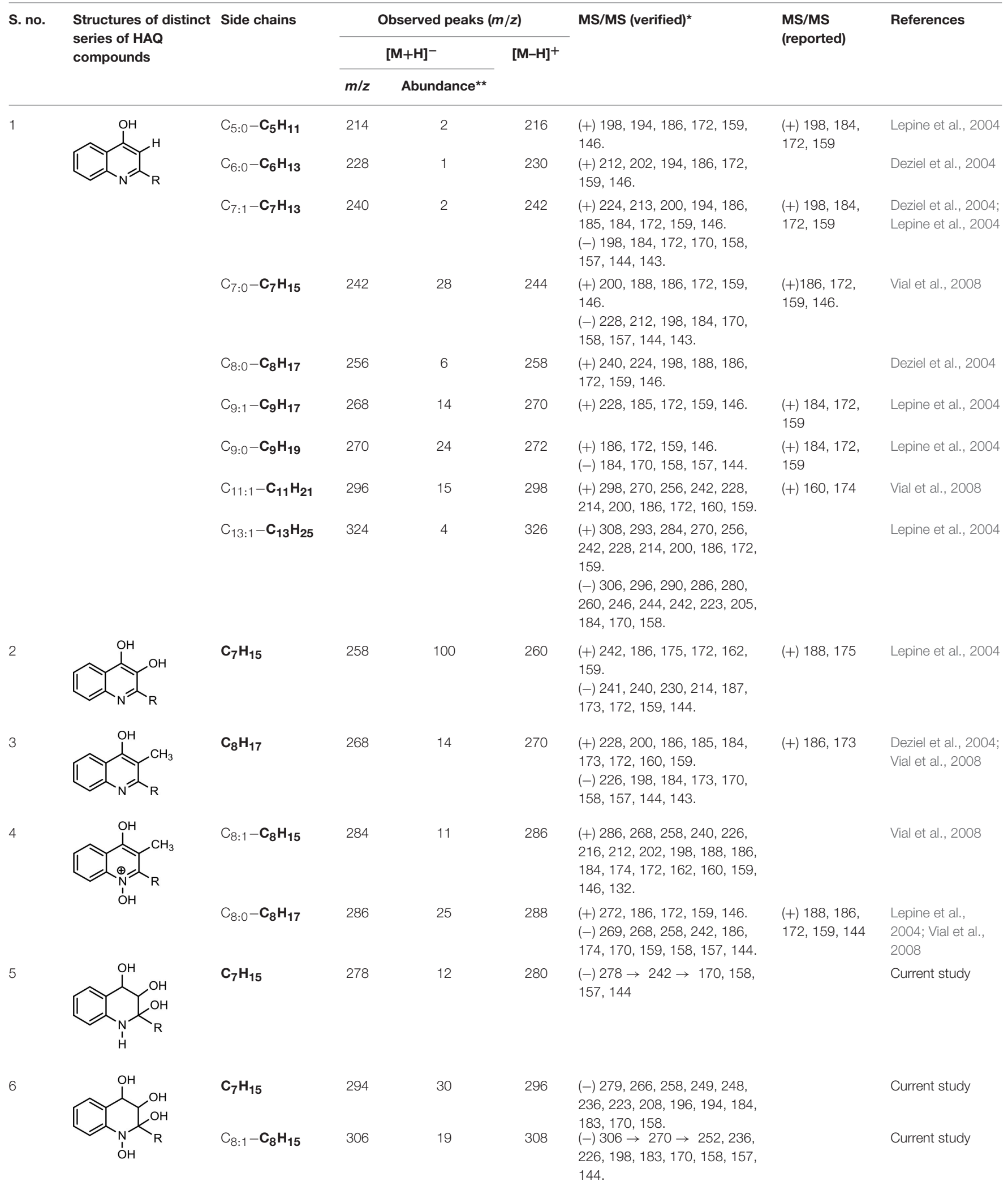


TABLE 2 | Continued

\begin{tabular}{|c|c|c|c|c|c|c|c|c|}
\hline \multirow[t]{3}{*}{ S. no. } & \multirow{3}{*}{$\begin{array}{l}\text { Structures of distinct } \\
\text { series of } \mathrm{HAQ} \\
\text { compounds }\end{array}$} & \multirow{3}{*}{ Side chains } & \multicolumn{3}{|c|}{ Observed peaks $(m / z)$} & \multirow[t]{3}{*}{ MS/MS (verified)* } & \multirow{3}{*}{$\begin{array}{l}\text { MS/MS } \\
\text { (reported) }\end{array}$} & \multirow[t]{3}{*}{ References } \\
\hline & & & \multicolumn{2}{|c|}{$[\mathrm{M}+\mathrm{H}]^{-}$} & \multirow[t]{2}{*}[\mathrm{M}-\mathrm{H}]{$^{+}$} & & & \\
\hline & & & $m / z$ & Abundance $^{\star \star}$ & & & & \\
\hline 7 & & $\mathrm{C}_{12: 1}-\mathbf{C}_{\mathbf{1 2}} \mathbf{H}_{\mathbf{2 3}}$ & 340 & 7 & 342 & $\begin{array}{l}(-) 322,312,297,291,277 \\
260,198,184,183,170,144 .\end{array}$ & & Lepine et al., 2004 \\
\hline
\end{tabular}

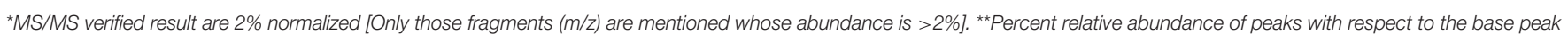
at $\mathrm{m} / \mathrm{z} 258$ (derived from negative ionization mode, Figure 2, Table-entry 2).

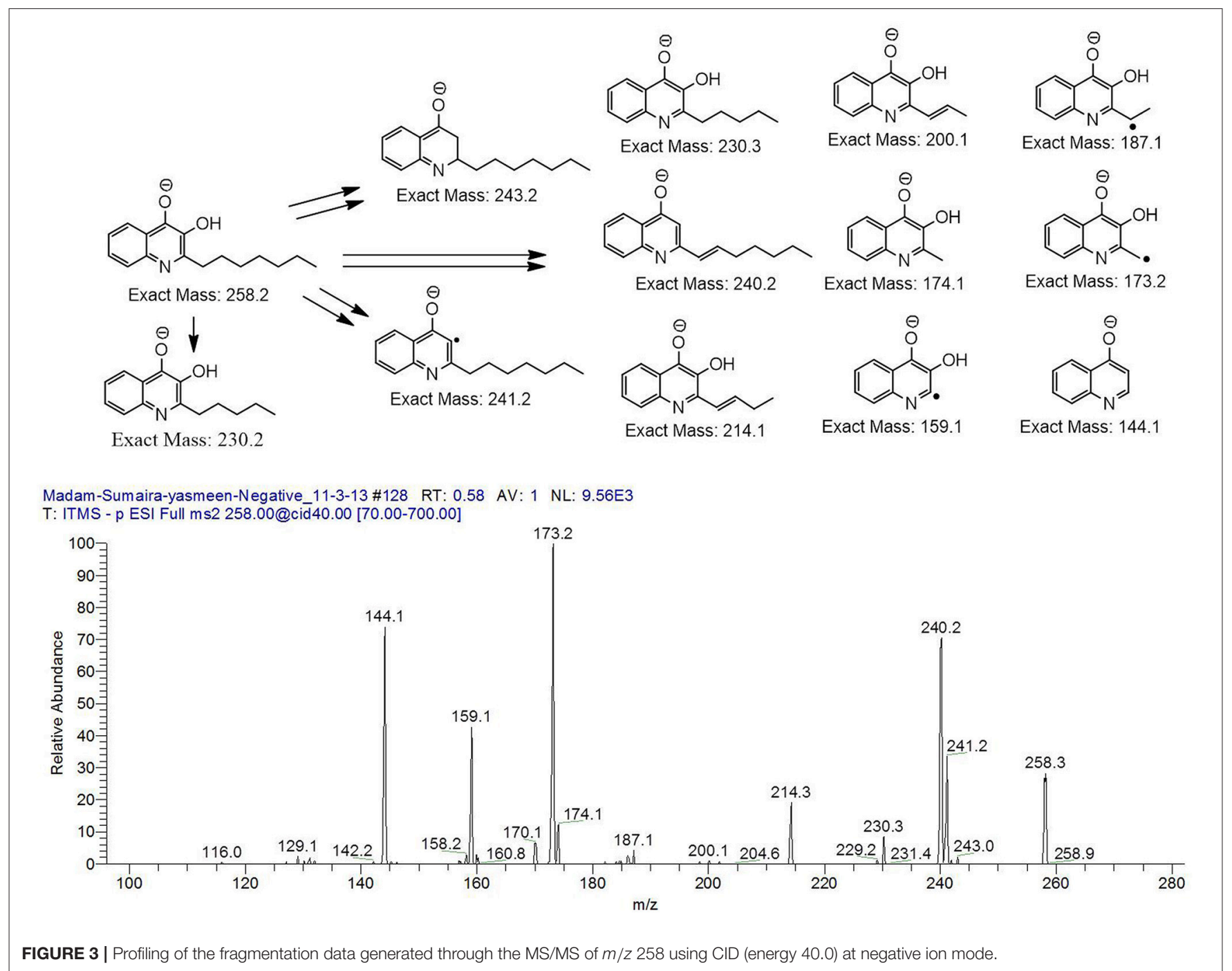

72 , and $144 \mathrm{~h}$ post-inoculation. Maximum activity of PAL was observed after 24 and $48 \mathrm{~h}$ of Xoo inoculation (Figure 7).

\section{Field Experiment}

Assessment of antagonistic strain BRp3 under field conditions was done at booting stage of rice variety Super Basmati. A prevalent virulent strain Xoo7 isolated in the present study was used for clip inoculation at booting stage. Application of $P$. aeruginosa strain BRp3 significantly reduced DLA i.e., $43 \%$ as compared with infected control i.e., $83 \%$. Maximum reduction in disease severity was recorded by foliar application of streptocyclin with $39 \%$ DLA but it was non-significantly different from that of the strain BRp3 (Figure 8). The lesion length was $6.2-8.6,5.6-9.9$, and $8.5-17.9 \mathrm{~cm}$ in treatments of BRp3, streptocyclin and infected control plants, respectively. $\mathrm{BRp} 3$ inoculated rice plants showed a significant increase in straw 


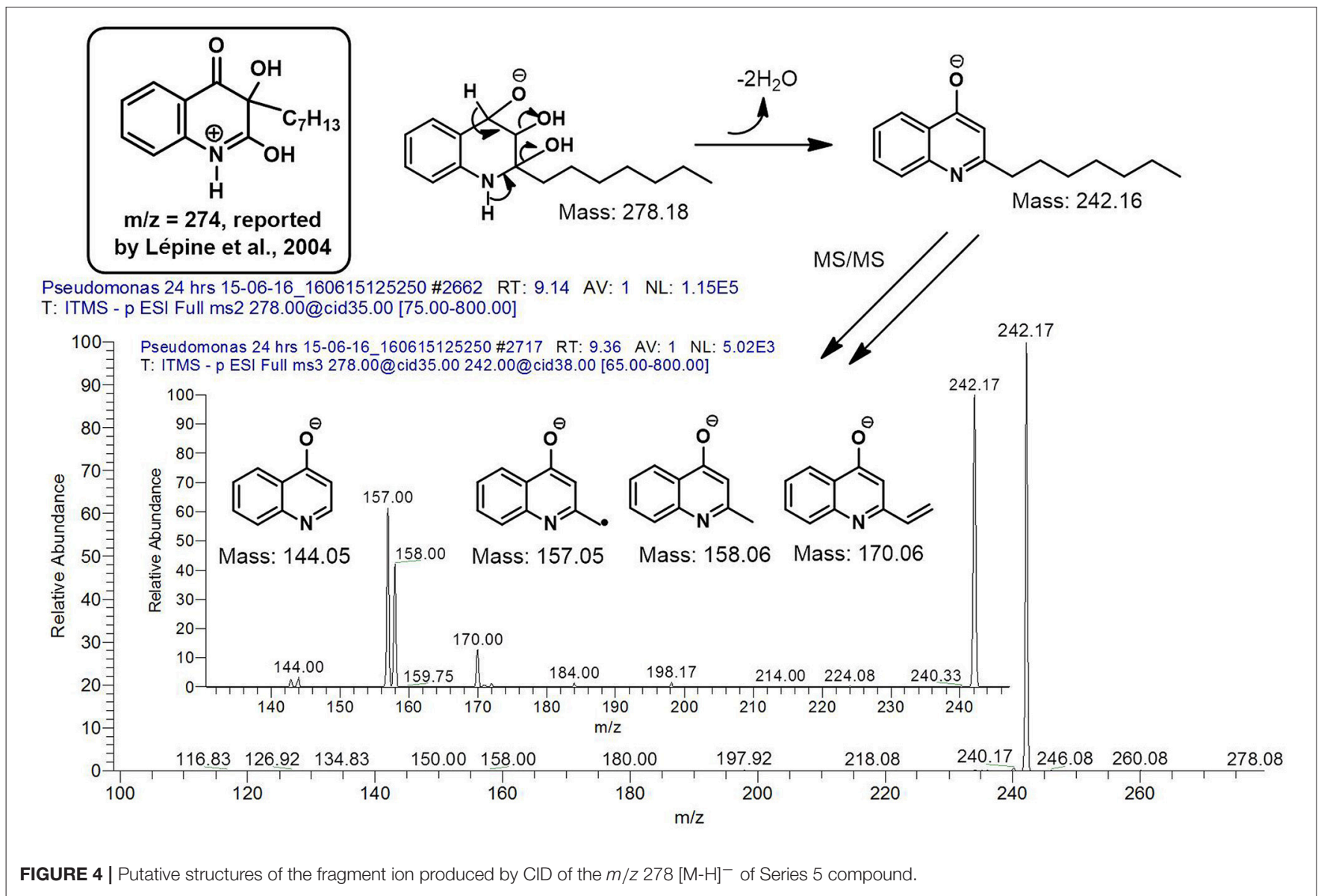

yield. Grain weight per plant was maximum with the strain BRp3 i.e., $34.2 \mathrm{~g} \mathrm{plant}^{-1}$ followed by healthy and streptocyclin treated plants. Minimum grain yield (19.8 g plant $^{-1}$ ) was observed for infected control plants (Figure 9).

\section{Field Evaluation for Yield Increase of Rice}

A field experiment was conducted to evaluate the inoculation effect of strain BRp3 on growth and yield of rice variety Super Basmati with different levels of fertilization. Application of the strain BRp3 either with $80 \%$ of the recommended doses or at full recommended doses of $\mathrm{N}$ and $\mathrm{P}$, significantly increased the growth parameters in rice compared to respective non-inoculated control plants. The inoculation with the strain BRp3 showed 55\% increase in straw and $51 \%$ in grain compared to non-inoculated control (with $80 \% \mathrm{~N}$ and P; Figure 10).

\section{Rhizosphere Colonization Studies}

Colonization studies under field conditions showed that total culturable indigenous bacterial population on rice roots as $\log _{10}$ 8.9-7.3 CFU g ${ }^{-1}$ root (Figure 11, Figure S8). The survival level of BRp3 however, declined gradually after seed treatment from $\log _{10} 8$ to $0.7 \mathrm{CFU} \mathrm{g}^{-1}$ root (Figure 12A). Total culturable indigenous bacterial counts on rice shoots were $\log _{10} 5.3$ 6.9 CFU $\mathrm{g}^{-1}$ shoot up to 40 days after sowing. The bacterial counts of strain BRp3 was $\log _{10}$ 3.9-1.1 CFU $\mathrm{g}^{-1}$ shoot when enumerated DPI while no colony of strain BRp3 was detected from surface-sterilized shoots of rice plant at 60 DPI (Figure 12B). Antibiotic resistance pattern (Table S3), in vitro suppression of Xoo growth (20 mm inhibition zone) and the other plant growth promoting traits like $\mathrm{P}$ solubilization (94 $\left.\pm 3 \mu \mathrm{g} \mathrm{mL}^{-1}\right)$, production of IAA $\left(28 \pm 2 \mu \mathrm{g} \mathrm{mL}^{-1}\right)$, and siderophores $12 \pm 2 \mathrm{mg} \mathrm{L}^{-1}$ ) of the inoculated bacterium were found comparable to those observed earlier for its pure culture.

Counts of total culturable bacteria on rice roots increased with plant growth. In the rhizosphere, the higher number $\left(\log _{10} 10.3 \mathrm{CFU} \mathrm{g}^{-1}\right.$ root) of bacteria was found on BRp3inoculated plants, followed by healthy control plants $\left(\log _{10} 9\right.$ CFU $\mathrm{g}^{-1}$ root) determined at 21 DPI. A decreasing pattern in the counts was more for infected (inoculated with Xoo only) and positive controls (streptocyclin) as compared to that of the strain BRp3 inoculated plots.

Colonization of $P$. aeruginosa $\mathrm{BRp} 3$ on rice roots was studied with the help of immunofluorescence (IF) assay and confocal laser scanning microscopy (CLSM). The primary antiserum raised against strain BRp3 was found to be strain specific (Figure S9). Strain BRp3 was found to colonize all over the rice roots at $100 \mathrm{X}$ resolution. No fluorescence was observed on the roots of un-inoculated plants (Figure 13A). Colonization was observed in intercellular spaces and in micro-colonies as well (Figures 13B-D). However, the number of BRp3 cells detected by confocal microscopy decreased gradually after 21 days of seed treatment. 


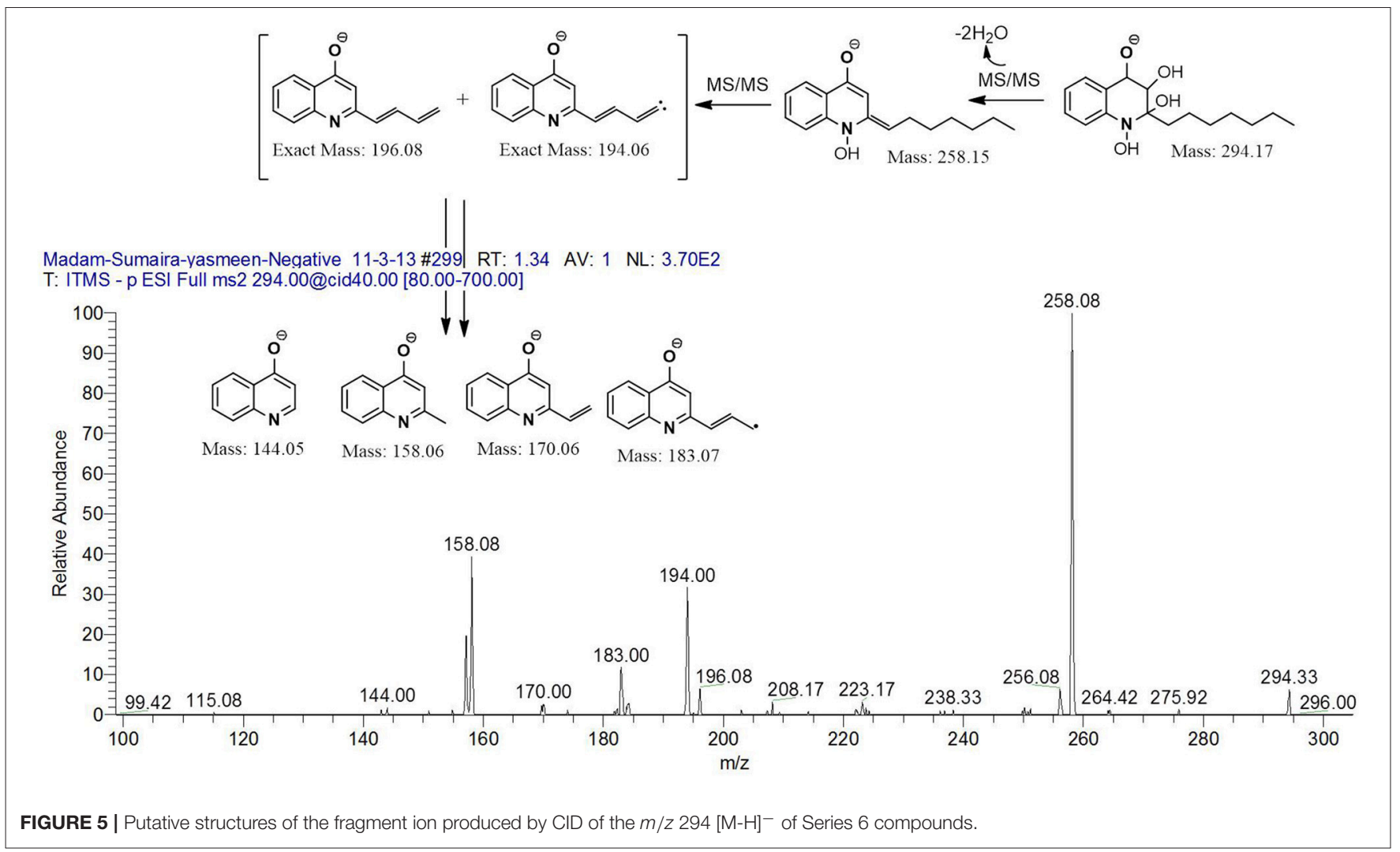

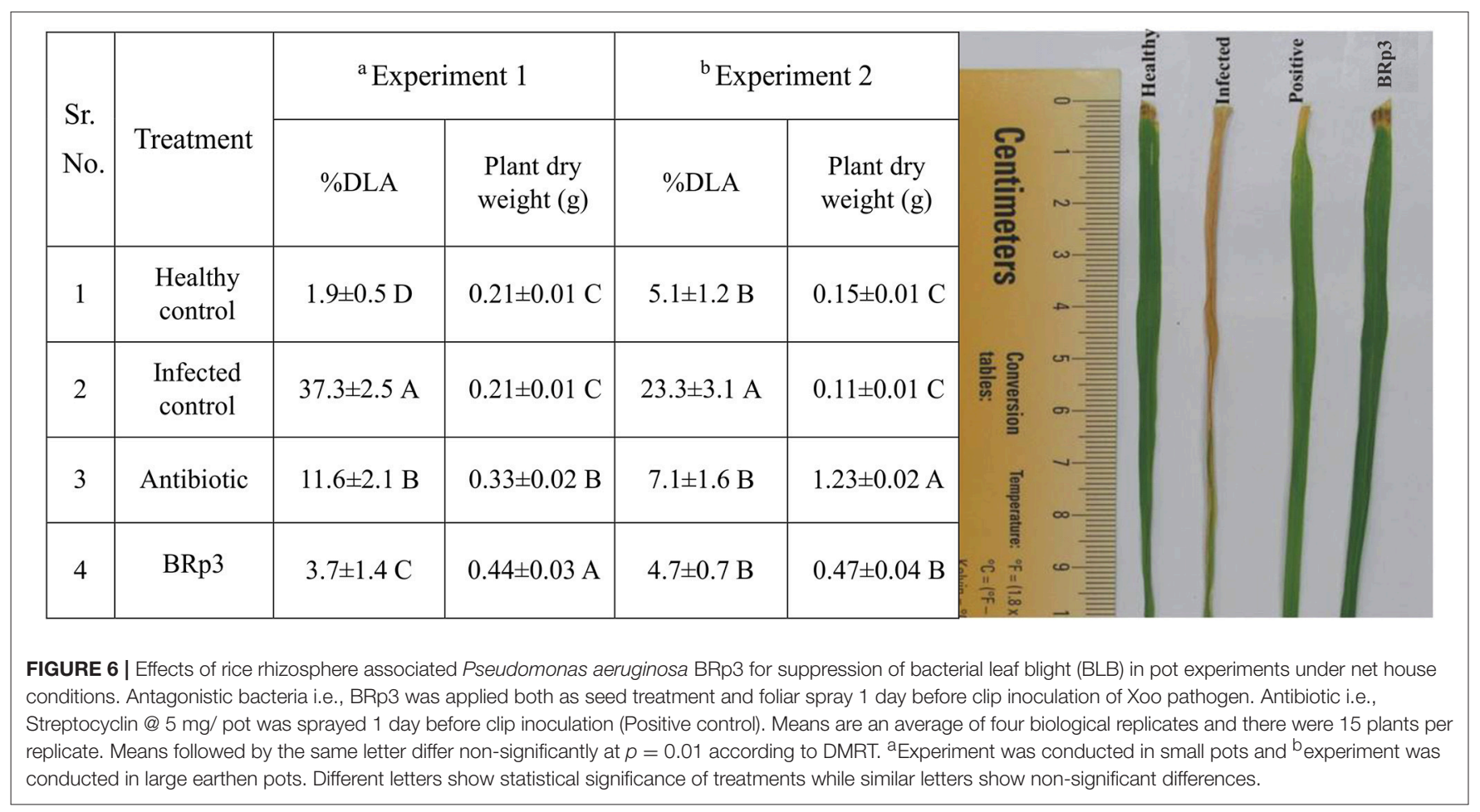




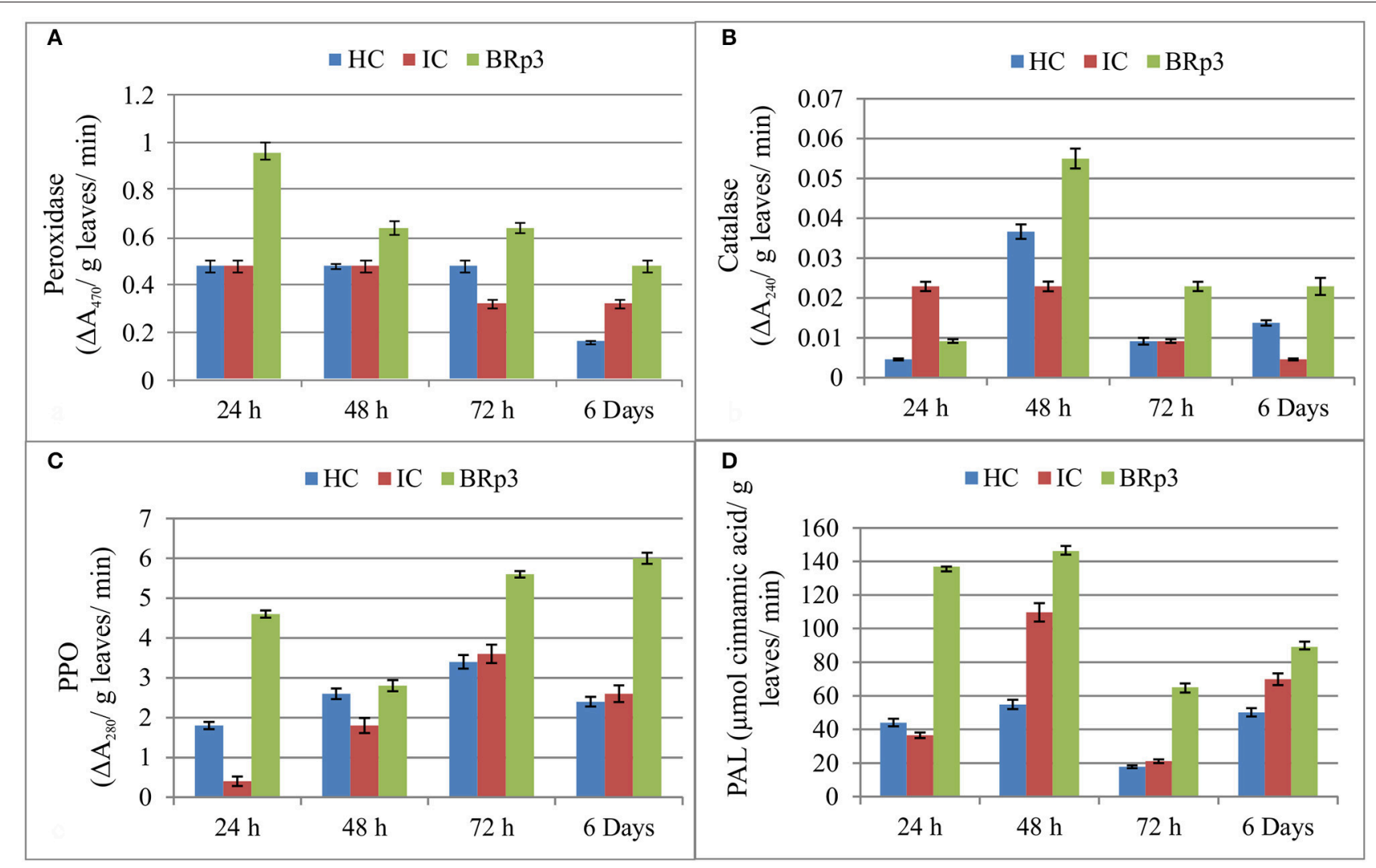

FIGURE 7 | Induction of defense related enzymes (A) Peroxidase (B) Catalase (C) Polyphenol oxidase (PPO) and (D) Phenylalanine ammonia lyase (PAL) in rice plants inoculated with Pseudomonas aeruginosa BRp3 and challenge inoculated with bacterial leaf blight causing pathogen. Healthy control (HC): Leaves of plants clip inoculated with distilled water, Infected control (IC): Leaves clip inoculated with BLB pathogen i.e., Xanthomonas oryzae pv. oryzae (Xoo). Forty leaves/ treatment were clip inoculated. Bars show standard deviation of four biological replicates and each replicate has 15 plants per replicate.

\section{DISCUSSION}

Plant-associated beneficial bacteria are important growth promoters or biocontrol agents in modern agriculture where eco-friendly and sustainable approaches are growing and have more acceptance than ever before. Rice is grown on large area of Pakistan where a lot of chemical fertilizers as well as pesticides are applied. This study was carried out to evaluate the potential for rhizobacterial inoculum to promote growth and to control disease in rice.

The pathogenicity of $X$. oryzae strains to rice confirmed their identity as causal pathogen of BLB. Xoo1 and Xoo2 were used for further studies due to their aggressive behavior. In vitro plate assay for screening the rhizobacterial isolates (512) for inhibition of growth of Xoo led to the selection of $P$. aeruginosa BRp3 for further studies. In a previous study, only LB medium was used for isolation of antagonistic bacteria and the frequency of antagonistic bacteria among the total isolated bacterial population was low (Yasmin et al., 2016). A relatively higher number of antagonistic bacteria was obtained in the present study when different growth media (Nutrient Agar, King's B, and Gould's S1) were used for isolation of bacterial populations. As the biocontrol agents with broad spectrum antagonism are found to be more effective against phytopathogens in rhizosphere, therefore, the antagonistic bacteria isolated in the present study were also screened against different phytopathogens, other than the target pathogen (Table S1). Several rice varieties are infected by various fungal pathogens, including Fusarium spp. that cause bakanae disease in rice (Desjardins et al., 2000). The suppression of in vitro growth of the Fusarium spp. by the antagonistic bacteria showed its potential use as an inoculant for biocontrol of these fungal pathogens.

Phosphate solubilizing and IAA producing microbes are a vital fraction of the microbes that improve the development and growth of their host plant. Vassilev et al. (2006) reported that the solubilization of insoluble phosphates by microbial activity usually induce the secretion of certain metabolites mainly siderophores, lytic enzymes and phytohormones that are involved in the control of phytopathogens. The intrinsic resistance of strain BRp3 against different antibiotics may aid survival in the rhizosphere whenever used as a biological control agent (Dobereiner and Baldani, 1997). In our previous study, siderophore production and P-solubilization were found to be involved in growth promoting activities of antagonistic $P$. aeruginosa Rh323 (Yasmin et al., 2016) whereas the present study suggests that $\mathrm{P}$ solubilization accompanied with the production 


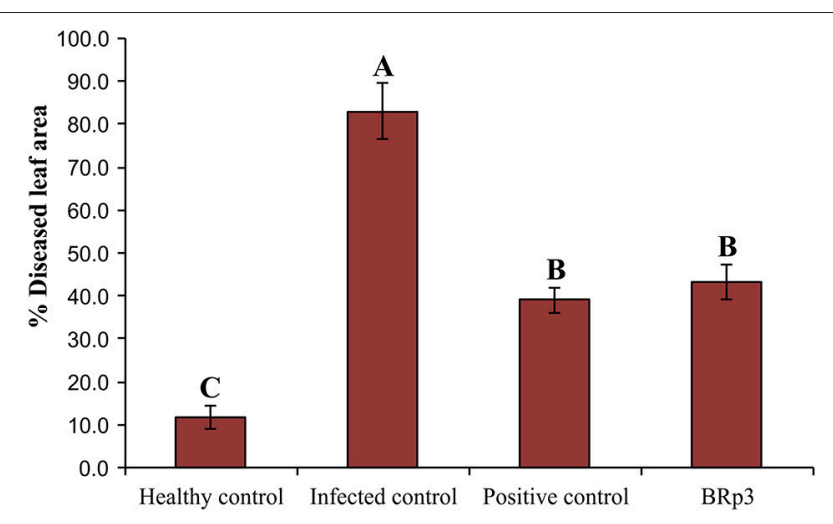

FIGURE 8 | Evaluation of Pseudomonas aeruginosa BRp3 for suppression of bacterial leaf blight (BLB) under field conditions. Healthy control: Leaves of plants clip inoculated with distilled water, Infected control: Leaves clip inoculated with prevalent BLB pathogen i.e., Xanthomonas oryzae pv. oryzae (Xoo) strain isolated in the present study; Positive control: Leaves clip inoculated with BLB pathogen and plants sprayed with streptocyclin and Pseudomonas sp. BRp3: Leaves clip inoculated with BLB pathogen and plants sprayed with liquid culture of strain BRp3. Sixty leaves/ treatment were clip inoculated. Four plants per replicate were sown in $1 \mathrm{~m}$ row. Suppression of BLB was measured in terms of reduction in the mean bacterial blight lesion length on treated leaves compared to those of non-inoculated control. Bars show standard deviation of three biological replicates. Means followed by the same letter differ non-significantly at $p=0.05$ according to DMRT.

of IAA, siderophore and ACC may contribute to the growth promoting activities of BRp3, even in the presence of Xoo. ACC deaminase activity of this strain may help to lower the level of ACC caused by ethylene under stress conditions and protect the host plant. Bacterial ACC-deaminase is known to regulate plant growth under biotic and abiotic stress conditions (Singh and Jha, 2016).

It is necessary to understand the mechanisms involved in the suppression of pathogens by the application of biocontrol agents for effective disease management. The bio-antagonistic bacterium used in the present study was characterized for different biocontrol determinants i.e., $\mathrm{HCN}$, chitinases, proteases, starch hydrolysis and siderophores production. Strain BRp3 produced volatile compounds such as HCN which is a known suppresser of phytopathogens (Brimecombe et al., 2001). Recent literature reported that cyanide producing bacteria can be considered as effective biocontrol agents because cyanide production by the bacterial strains induces resistance in the plant (Devi and Kothamasi, 2009; Spence et al., 2014). Gandhi et al. (2009) reported the production of an antifungal protease by rice rhizosphere associated Chryseobacterium aquaticum PUPC1 and its effects on the mycelial growth, germination of spores, and sclerotia of phytopathogenic fungi. It has been reported that chitinase can function in defense against many fungal pathogens and also correlated with induced resistance (Perez et al., 2002). Starch hydrolysing ability of the strains indicated their capability to produce amylase and to use a complex carbon source, which aids in the defensive mechanisms of bacterial strains (Marten et al., 2000).

There are many reports that highlight the importance of secondary metabolites in the biocontrol of plant pathogens
(Heeb et al., 2011; Khare and Arora, 2011; Jayaseelan et al., 2014). P. aeruginosa BRp3 has the capability to produce a variety of metabolites, which include siderophores (1-hydroxyphenazine, pyocyanin and pyochellin), rhamnolipids and a series of already characterized 4-hydroxy-2-alkylquinolines (HAQs) as well as novel 2,3,4-trihydroxy-2-alkylquinolines and 1,2,3,4tetrahydroxy-2-alkylquinolines. Mass spectrometric analysis has confirmed their structures (Figures 1, 2, Table 2).

Siderophores have also been reported to induce systemic acquired resistance (Trivedi et al., 2008; Sulochana et al., 2014). $P$. aeruginosa BRp3 produces 1-hydroxy-phenazine, pyocyanin (Figure 1) and pyochelin $(\mathrm{m} / \mathrm{z} 325$, Figure 2). Phenazine produced by non-pathogenic strain of $P$. aeruginosa has been documented as an antifungal metabolite on the basis of NMR and MS analyses (Kumar et al., 2011). Pyochelin produced by $P$. aeruginosa showed antagonistic activity against Botrytis cinerea, the phytopathogen of groundnut (Khare and Arora, 2011). Purified pyocyanin produced by $P$. aeruginosa TO3 was reported for its inhibitory effect against Macrophomina phaseolina in tomato (Audenaert et al., 2002).

Rhamnolipids are widely reported to be produced by various microbes including the Pseudomonas spp. (Chong and Li, 2017). $P$. aeruginosa BRp3 demonstrated the production of monoand di-rhamnolipids (ranged from $m / z 500$ to 650, Figure 2). LCMS analysis confirmed that the rhamnolipids produced by $P$. aeruginosa DR1 inhibited the growth of different plant pathogens like F. oxysporum, Sclerotium rolfsii, Phytophthora nicotianae, and M. phaseolina (Reddy et al., 2016).

$P$. aeruginosa $\mathrm{BRp} 3$ is capable of producing a large repertoire of HAQ and HAQ-related compounds in addition to the siderophores and rhamnolipids. Mass spectrometric analysis of cell free extract revealed the presence of nine analogs of 4-hydroxy-2-alkyl HAQs, having saturated and unsaturated alkyl carbon chains, varied from $\mathrm{C}_{5}$ to $\mathrm{C}_{13}$ chain length, exhibiting $\mathrm{m} / \mathrm{z}$ values of $216-326[\mathrm{M}+\mathrm{H}]^{+}$(Table 2, Serial No. 1). Their fragmentation data, can confirm their structures, which is well correlated with previously reported literature data (Deziel et al., 2004; Lepine et al., 2004; Vial et al., 2008). Only one analog of the structure representing 3,4dihydroxy-2-heptyl (HHAQ) was identified (Figure 3). HHAQ has demonstrated the highest peak intensity at $m / z 258$ (Figure 2), this compound also termed as "Pseudomonas Quinolone Signal" (PQS) and is involved in the mechanisms of cellular communication, to detect the pseudomonas cell density (Deziel et al., 2004).

Interestingly, putative polyhydroxy HAQ analogs, i.e., a 2,3,4trihydroxy-2-alkylquinoline $m / z 278[\mathrm{M}-\mathrm{H}]^{-}$and two analogs of 2,3,4-trihydroxy-2-alkylquinoline $N$-oxideat $\mathrm{m} / z 294$ and 306 $[\mathrm{M}-\mathrm{H}]^{-}$, respectively, were found to be present in crude extract (Series 5 and 6 compounds, Table 2). The fragmentation data correlated with the putative structures of these polyhydroxy HAQs (Figures 4, 5). Budzikiewicz and Kesselmeier (1979) and Neuenhaus et al. (1979) reported the putative 3-alkyl-3hydroxy-2, 4-dioxo-1, 2, 3, 4-tetrahydroquinoline derivatives in Pseudomonas. To support the theme of 3-alkyl substitution, they further synthesized these compounds (Figure S5). Similarly, in a detailed study conducted by Lepine et al. (2004) on 


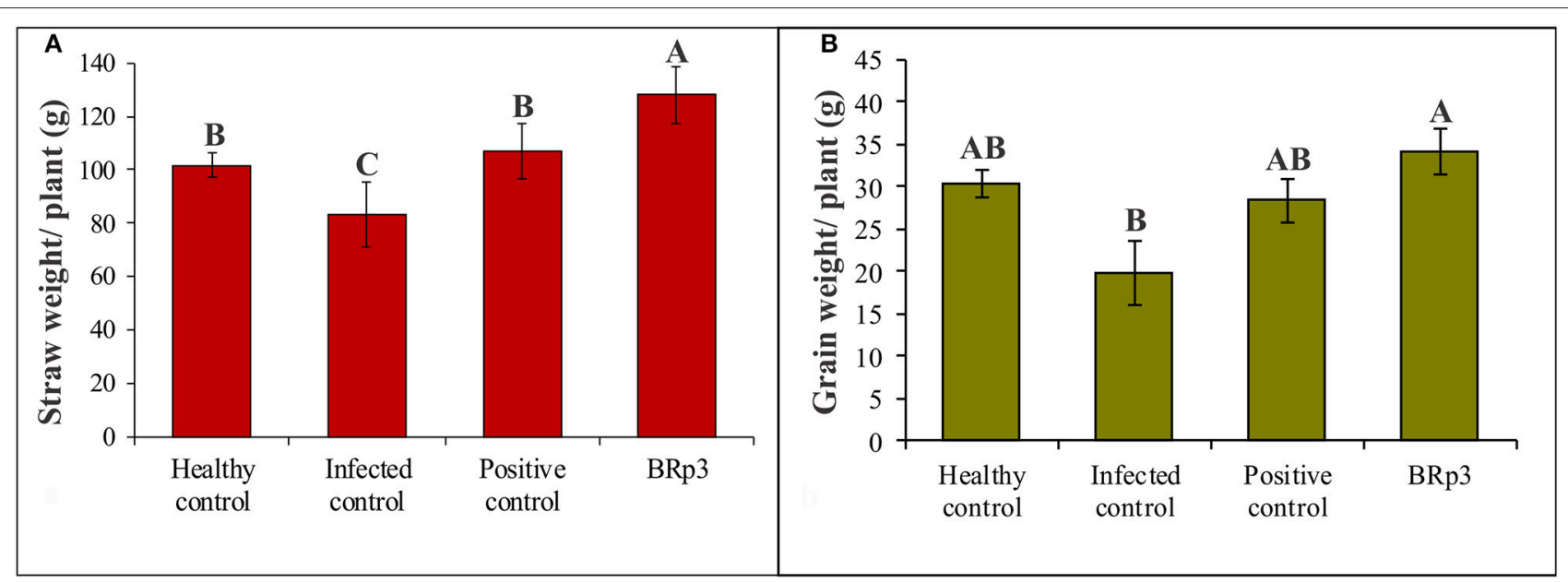

FIGURE 9 | Effects of Pseudomonas aeruginosa BRp3 on yield parameters of rice in the presence of Xoo pathogen. (A) Straw weight and (B) grain weight. Four plants per replicate were sown in $1 \mathrm{~m}$ row; Bars show standard deviation of three biological replicates. Means followed by the same letter differ non-significantly at $p=$ 0.05 according to DMRT.

metabolic profiling of HAQs from Pseudomonas, polyhydroxy HAQs were spotted but the alkyl side chain was reported on 3-position. However, to the best of our knowledge the polyhydroxy HAQs representing alkyl groups at 2-position of the heterocyclic rings, have not been reported in Pseudomonas species before this study. To support our theory of alkyl substitution at 2-position, the proposed 2,3,4-trihydroxy-2alkylquinoline at $m / z 278$ was fragmented through CID that generated predominant daughter ion at $\mathrm{m} / z$ 242, which on further fragmentation yielded similar finger prints of ions as produced by 4-hydroxy-2-heptylquinolines (Table 2, Serial 1; Figure S6). Finally, a 4-hydroxy-2-dodecenylquinoline $\mathrm{N}$-oxide analog at $m / z 340[\mathrm{M}-\mathrm{H}]^{-}$was identified, whose MS/MS data was correlated with the proposed structure (Table 2, Serial No. 7). The production of this HAQ by Pseudomonas, has also been reported by Lepine et al. (2004). Pseudomonas aeruginosa and other related bacteria produced 2-alkyl-4(1H)quinolones, which exhibited antimicrobial activity (Heeb et al., 2011).

This work demonstrates that $P$. aeruginosa BRp3 is capable of producing a large repertoire of HAQ and HAQ-related compounds in addition to the siderophores and rhamnolipids. Identification of polyhydroxy HAQs may provide insight about the biosynthetic pathway of these interesting compounds. These HAQs along with siderophores in the presence of rhamnolipids (as emulsifying and bacterial cell membrane disrupting agents), may be collectively responsible for the profound antibacterial activity of BRp3 against Xoo. Further studies are needed to establish the individual role of each detected secondary metabolite entity as an active biocontrol agent against BLB pathogen. But the challenge to such study is to get these metabolites in measurable quantity in their purified form. Since these metabolites are being produced in nano grams concentration, the optimization of their production through fermentation would have to be optimized prior to their purification process. Secondly, their purification is challenging, owing to the slight variation in their structures, polarity, hydrophobicity etc. (especially the HAQs), and a routine silica column chromatography was failed to purify them. Although, Naureen et al. (2017) have successfully purified the secondary metabolites (2-pentyl-4-quinolinecarboxylic acid and 1- methylcyclohexene) from Lysinibacillus sphaericus ZA9 but the chemistry of these metabolites is significantly different from the HAQs identified in the present study. A high-quality preparatory HPLC system may be required to purify various analogs of HAQs (Wang et al., 2011).

Due to the aforementioned technical challenges, obtaining the sufficient quantities of purified metabolites for plant assays looks difficult. However, crude supernatant from pure cultures of BRp3 were shown to suppress the BLB pathogen (Figure S7). The extracted supernatant of antagonistic bacterial culture has been reported for the control of phytopathogens during in-planta evaluation (Simonetti et al., 2012). The extracellular filtrates of biocontrol bacteria having different secondary metabolites such as cyclic lipopeptides were found to be responsible for their antifungal activity (Petatan-Sagahon et al., 2011). Few reports have documented the significant pathogen suppression by supernatants of fermentation without extraction (Garcia et al., 2014). The mechanistic suppression of BLB can be supported by the fact that rice plants inoculated with the strain BRp3 and challenge inoculated with BLB pathogen resulted in an increased activity of defense related enzymes in the host plant. In a previous study, accumulation of defense related enzymes was observed in rice plant up to $48 \mathrm{~h}$ after foliar application of antagonistic bacteria Rh323 (Yasmin et al., 2016). Plants inoculated with BRp3 exhibited an increase in the activity of POD, CAT, and PAL after 24 and $48 \mathrm{~h}$ post inoculation while, PPO activity was observed even after $72 \mathrm{~h}$ and up-to 6 days after challenge inoculation. The production of plant defensive enzymes i.e., POD, PPO, CAT, and PAL in response to inoculated PGPR bacteria is associated with ISR in plants against the pathogen (Saikia et al., 2006; Liang et al., 2011). 


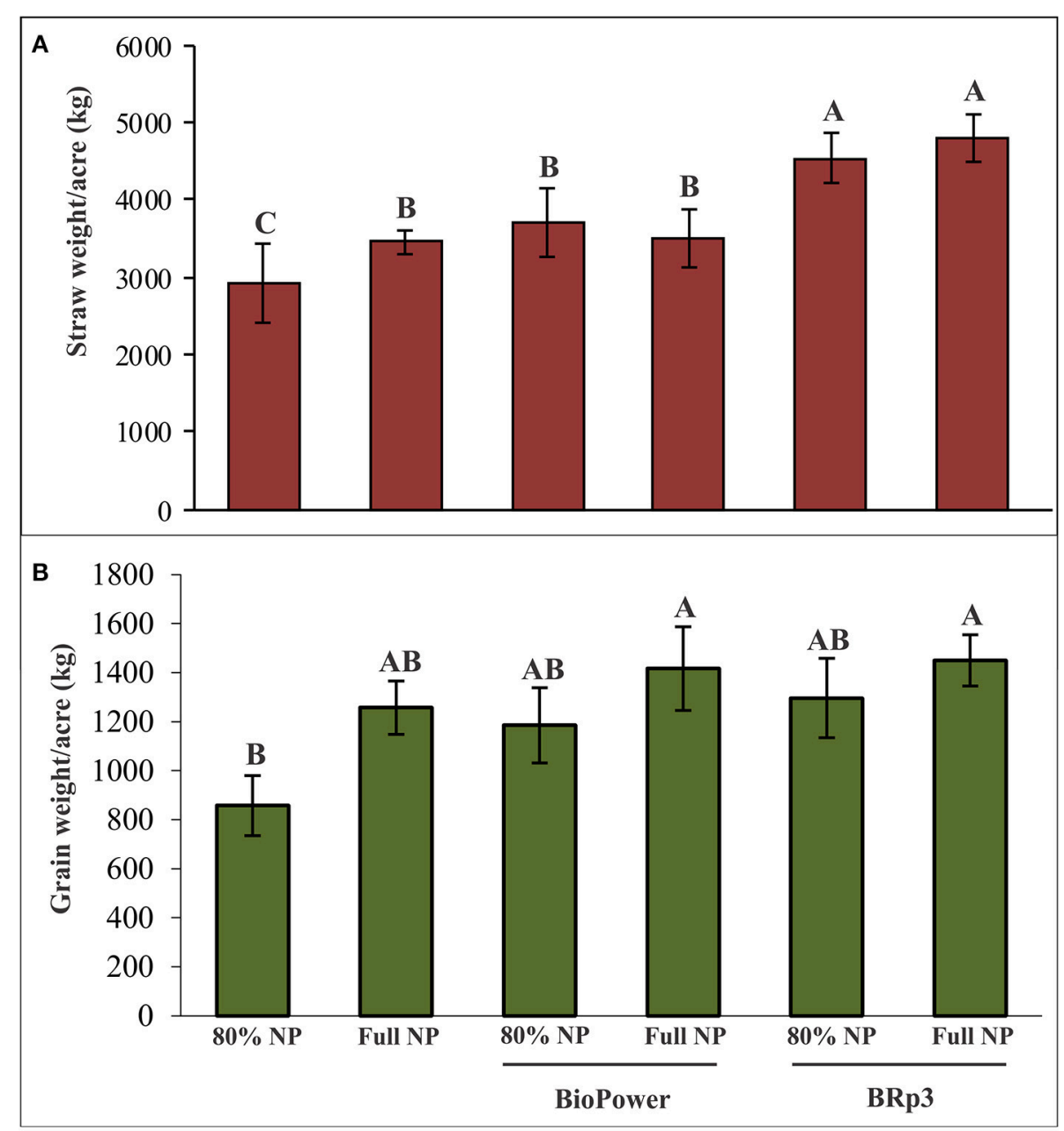

FIGURE 10 | Effects of Pseudomonas aeruginosa BRp3 on yield parameters of rice variety Super Basmati in a field experiment in the absence of Xoo pathogen. (A) Straw weight and (B) grain weight. Un-inoculated with $80 \%$ of the recommended doses of nitrogen (N) and Phosphorus (P) fertilizers. Un-inoculated with full dose of the recommended $\mathrm{N}$ and $\mathrm{P}$ fertilizers. "BioPower" a consortium of bacterial strains is a commercial biofertilizer product of NIBGE. Bars show standard deviation of four biological replicates. Means followed by the same letter differ non-significantly at $p=0.05$ according to DMRT. Plot size was $28 \mathrm{~m}^{2}$.

A better evaluation of plant growth promoting efficiency of the bacterial agents under net house conditions is one of the prerequisites for transferring a strategy from the laboratory into the field. $P$. aeruginosa BRp3 showed effective and consistent pathogen suppression in different pot experiments conducted under net house conditions with different strains of BLB pathogen as indicated by significantly reduced diseased leaf area as compared to the respective non-inoculated control (infected control) as well as compared to positive control of streptocyclin treated plants. Velusamy et al. (2006) reported 58.8 and $64.5 \%$ BLB suppression by a DAPG producing P. fluorescens PTB9 in net house and field experiments, respectively. Literature showed that the application of $P$. fluorescens Pf1 treatment effectively controlled BLB and the treatment was found to be more effective than the standard streptocyclin in controlling the disease as well as in increasing the yield (Vidhyasekaran et al., 2001).
Field experiments conducted in the presence of Xoo indicated that inoculation with $P$. aeruginosa BRp3 significantly reduced diseased leaf area compared to respective non-inoculated control (infected control) but non-significantly compared to positive control of streptocyclin treated plants. Strain BRp3 showing suppression of BLB equivalent to the positive control under field conditions can be considered as a promising biological control agent to suppress Xoo in rice. Root or seed inoculation of rice plants with this bacterium provided protection to the plant against BLB at early growth stages while its foliar spray at later growth stage or maximum tillering stage protected the rice plant from subsequent disease incidence. Various secondary metabolites produced by this strain along with $\mathrm{HCN}$, may be responsible for the suppression of phytopathogens. The production of increased biomass by inoculated BRp3 may be induced by the production of IAA or siderophores. Different studies reported enhanced growth of root-shoot length 


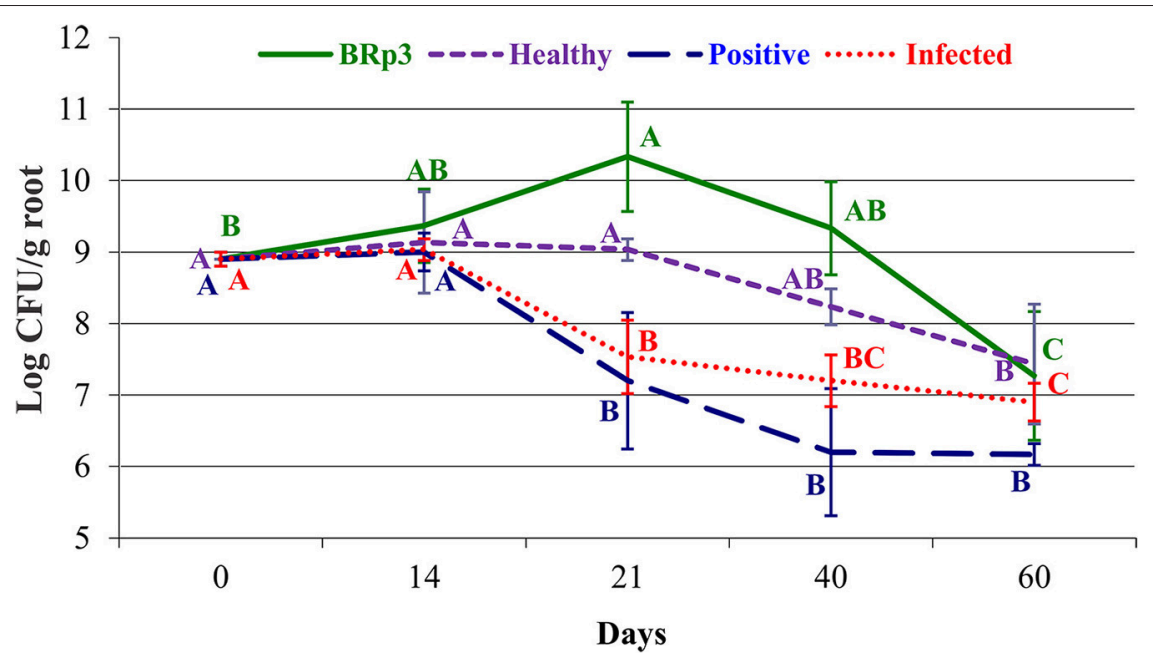

FIGURE 11 | Rice root colonization in response to different treatments in a field experiment. Pseudomonas aeruginosa BRp3 was applied both as seed treatment and foliar spray 1 day before clip inoculation of rice bacterial blight pathogen. Foliar spray of antibiotic streptocyclin was used as positive control while non-inoculated plants with and without pathogen, were used as infected and healthy controls, respectively. Bars represent the standard deviation of three biological replicates. Four plants per replicate were sown in $1 \mathrm{~m}$ row and three root samples from each replicate were collected. Means followed by the same letter differ non-significantly at $p=$ 0.05 according to DMRT. CFU, Colony forming units represent total viable count.

of cucumber, lettuce, potato and tomato due to inoculated Pseudomonas strains (Weller, 2007). Khare and Arora (2010) reported the role of IAA produced by $P$. aeruginosa in the suppression of charcoal rot disease of chickpea. Different types of siderophores such as pesudobactin and pyoverdine produced by rhizospheric bacteria chelate to the available form of iron present in the soil and suppress the pathogens by reducing the availability of iron for the phytopathogen (Wensing et al., 2010; Sulochana et al., 2014). Notably, the number of rhizosphereassociated Pseudomonas species involved in yield enhancement (Combes et al., 2011) and/or reduction in plant diseases, are increasing (Couillerot et al., 2009; Beneduzi et al., 2012).

The inoculated bacteria BRp3 supplemented with $80 \%$ of the recommended doses of $\mathrm{N}$ and $\mathrm{P}$ significantly enhanced the grain and straw yield with 51 and 55\% increase, respectively as compared to the respective control. The single inoculated strain BRp3 showed yield increase comparable to that of commercial biofertilizer (BioPower). Application of strain BRp3 either with $80 \%$ of the recommended doses or at full/ recommended doses of $\mathrm{N}$ and $\mathrm{P}$, significantly improved the growth parameters in rice variety Super Basmati in comparison with control plants without inoculation provided with the same doses of $\mathrm{N}$ and $\mathrm{P}$. BioPower treatment also significantly increased the grain weight and straw weight even with $80 \%$ of the recommended doses of nitrogen and phosphorus (Figure 10). The inoculation effect of BRp3 on straw and grain yield with different levels of fertilization indicated that the inoculated bacteria may contribute equal to that of the $80 \%$ of the recommended doses of $\mathrm{N}$ and $\mathrm{P}$ indicating that it may save $20 \%$ of urea and DAP fertilizers during crop growth season. These results suggest that the rhizobacteriainoculants can be applied after further evaluation for nutrient management programs. Adesemoye et al. (2009) reported that supplementing $75 \%$ of the recommended fertilizer rate with inoculants produced plant growth, yield, and nutrient ( $\mathrm{N}$ and P) uptake that were statistically equivalent to the full fertilizer rate without inoculants. The use of fertilizer at rates below the recommended dose, in the absence of bioinoculants, resulted in inconsistent effects on the plant with significant reduction in nutrient uptake and yield. In a previous study by Yasmin et al. (2016), inoculation of Pseudomonas spp. and Serratia sp. had a significant effect on rice growth under net house conditions and the grain yield was increased in the field too when used in mixed consortia but the effect of field inoculation was non-significant compared to the respective control. In the present study, BRp3 as a single inoculum, not only suppressed the pathogen under field conditions but also improved the rice yield significantly. The factors contributed for higher grain yield due to strain BRp3 as compared to the previously isolated antagonistic strains may be due to its higher potential for IAA and siderophores production. The siderophores produced were also evidenced by LCMS analysis.

Several studies have demonstrated better plant protection when the inoculated bacteria with improved rhizospherecompetence were used (Bonaldi et al., 2015). Colonization studies of $P$. aeruginosa BRp3 under field conditions using viable count showed that the strain had the potential to colonize on rice roots as well as on shoots up to 60 days (Figures 12, 13). Green colored colonies and pigmentation were the main characteristics of $P$. aeruginosa BRp3 that facilitated its detection from the roots and shoots of rice among indigenous soil populations under field conditions using viable count method. Colonization studied by IF and CLSM was in accordance with the results of viable counts of strain BRp3. It appeared that strain BRp3 colonized the rhizoplane and was also found as a shoot endophyte of rice plant. The number of most of the biological control agents decreases with time after their application in the environment, 


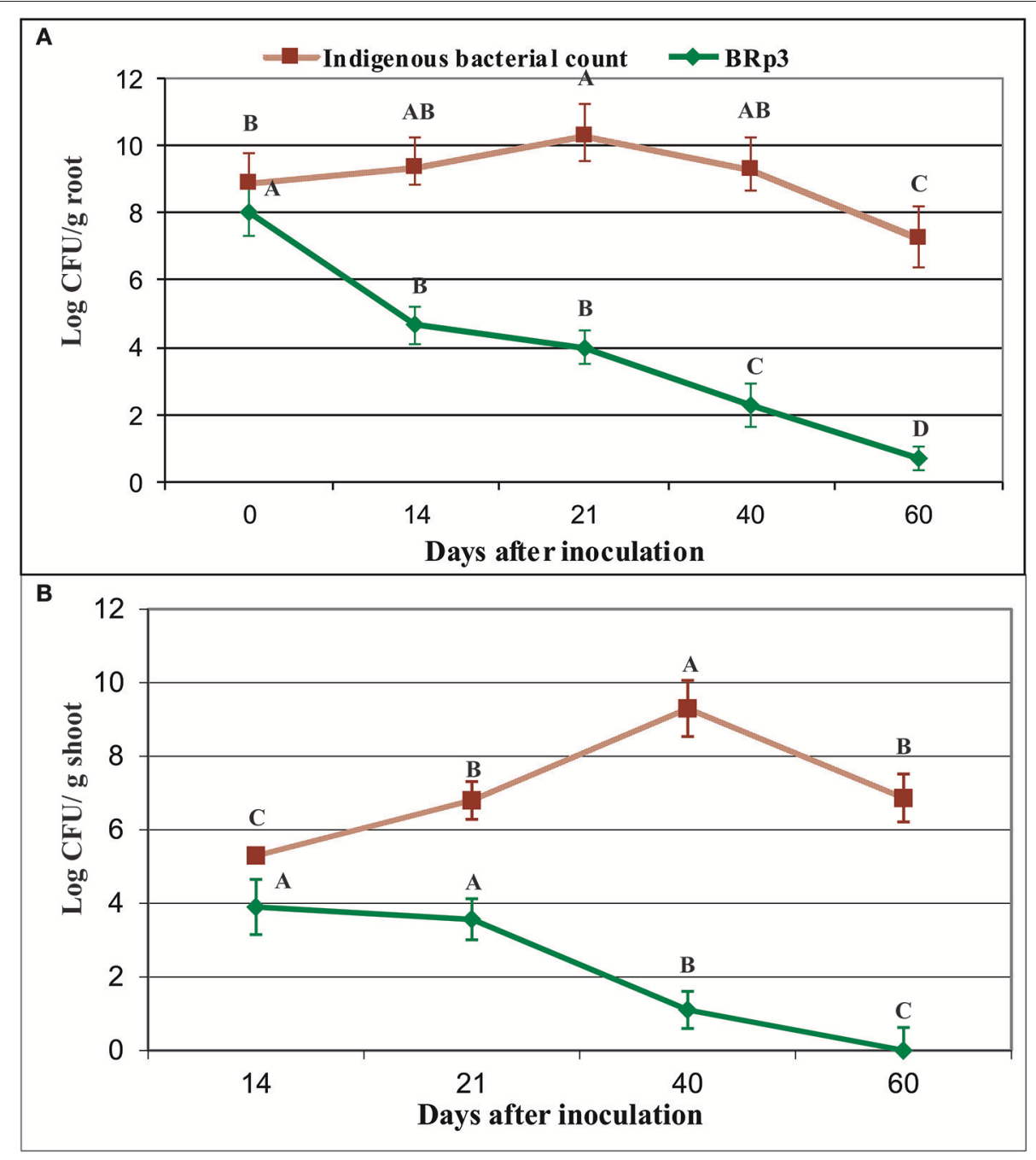

FIGURE 12 | Survival of Pseudomonas aeruginosa BRp3 on the roots (A) and shoots (B) of field-grown rice plants. Enumeration of bacterial population was determined by viable count method. Root and shoot samples were collected from field-grown rice plants. Four plants per replicate were sown in $1 \mathrm{~m}$ row and three root/shoot samples from each replicate were collected. Bars represent the standard deviation. Means followed by the same letter differ non-significantly at $p=0.05$ according to DMRT.CFU, Colony forming units.

which affect the synthesis of inhibitory metabolites produced by these bacteria (Ji et al., 2008). Efficacy of the biocontrol agent depends on the proportion of root-colonized bacterial cells of the antagonistic bacteria. The influence of the introduced strain $\mathrm{BRp} 3$ on indigenous microbiota was estimated by comparing the total culturable bacterial population levels with those of different treatments under field conditions. Detection of higher number of culturable bacterial population indicated that BRp3 inoculation did not decrease the native bacterial population, which may be involved to a certain extent for promoting the plant growth (Susana et al., 2007).

To study plant-interacting bacteria, such as phytopathogens, symbionts, endophytes, biocontrol agents, and rhizospheric bacteria requires demonstration of re-infection and establishment of the inoculated strain in or on field-grown plants (Berg et al., 2014). Efficient root colonization by fluorescent
Pseudomonas spp. has been reported to play an important role in their biocontrol activity against various plant pathogens (Bonaldi et al., 2015).

The significance of this study is that functionally characterized antagonistic $P$. aeruginosa BRp3 may be used for biocontrol of BLB along with enhanced rice growth. Even though, Pseudomonas spp. are indigenous and present in various rhizomicrobiomes but some of these can grow above $37^{\circ} \mathrm{C}$ and may become opportunistic pathogens, hence suitable biosafety regulations are needed to practically implement this technology for field application (Vilchez et al., 2016). P. aeruginosa BRp3 will be subjected to acute toxicity tests on mice to study the biosafety of this novel bacterial biocontrol agent. Absence of hemolytic activity on blood agar plates (Unpublished data) indicated that rhizospheric $P$. aeruginosa BRp3 may be unlikely to be a human pathogen (Radhapriya et al., 2015) but whole genome of this 

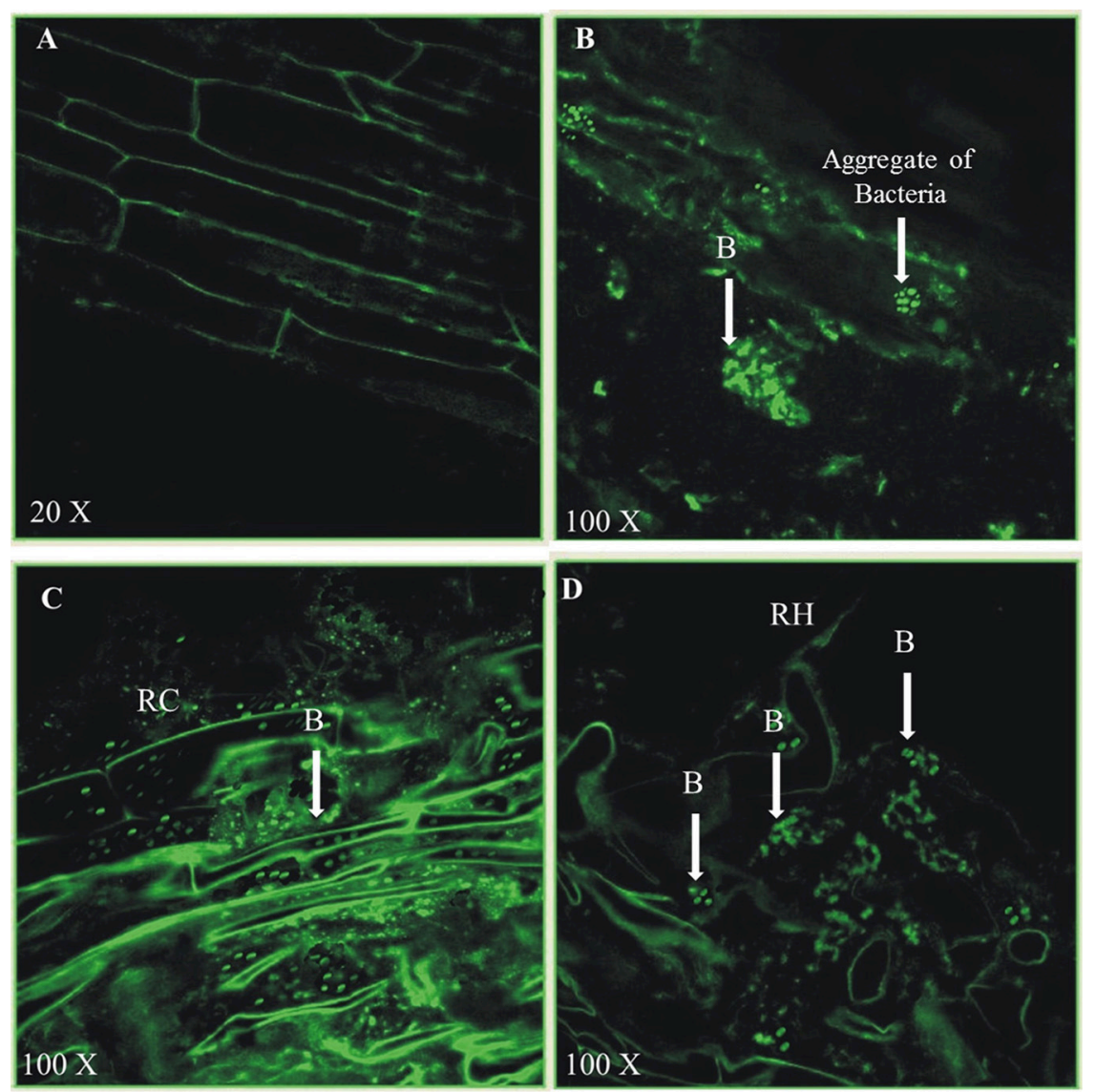

FIGURE 13 | Colonization of 21-days old rice roots by Pseudomonas aeruginosa BRp3 studied by fluorescence antibodies staining and CLSM. (A-D) FITC-Immunofluorescence images by confocal laser scanning microscopy (CLSM) of whole root after staining by fluorescent antibody (FA) technique. Un-inoculated control (A), Rice roots inoculated with Pseudomonas aeruginosa BRp3 (B,C) grown in sterile sand under net house conditions and (D) under field conditions. $\mathrm{B}$, Bacteria; RC, Root cell; $\mathrm{RH}$, Root hair.

bacterium will be sequenced and compared with non-pathogenic $P$. aeruginosa strains like ATCC 15442 (Wang et al., 2014) to better understand the pathogenicity for its safe application.

\section{CONCLUSIONS}

The study presents the detailed physiological characterization and effect of $P$. aeruginosa BRp3 inoculation on rice variety Super Basmati in the presence as well as in the absence of BLB pathogen. This bacterium produced a series of already characterized and novel analogs of HAQs, siderophores and rhamnolipids. The discovery of polyhydroxy HAQs may provide the insight about the biosynthesis pathway of these interesting compounds. The resistance was also induced in rice plants by BRp3 as the activity of defense related enzymes increased after pathogen inoculation. Collectively, the induction of defense related enzymes, HAQs along with siderophores in the presence of rhamnolipids and $\mathrm{HCN}$, were responsible for the profound antibacterial activity of BRp3 against Xoo pathogen. The increased biomass production by strain BRp3 may be attributed to the production of IAA and siderophores. The colonization of the inoculated BRp3 and its re-isolation from rhizosphere indicated its better survival and rhizosphere-competence. On the basis of overall results achieved during this study, bacterial strain BRp3 may be an effective bio-inoculant for Super Basmati rice after ensuring its biosafety aspects. This is perhaps the first systematic effort to use functionally well-characterized beneficial Pseudomonas sp. capable of diverse secondary metabolite production for biocontrol of BLB pathogen in the country.

\section{AUTHOR CONTRIBUTIONS}

SY was involved in conducting whole research work, data analysis, and write up. FH gave the basic idea to use beneficial bacteria as biocontrol agent and supervised the study. MM helped in 16S rRNA gene sequencing and edited the manuscript. MR helped in lab/field experiments and data analysis. HA provided reference strains of pathogen and involved in conducting experiments at NIAB. MZ helped in LC-MS analysis. MI did LC-MS analysis and edited the manuscript. 


\section{FUNDING}

The research was partially funded by Pakistan Science Foundation (Project: PSF/NSLP/P-NIBGE 319).

\section{ACKNOWLEDGMENTS}

We are highly grateful to Mr. Junaid Ahmed Khan, (Principal Scientist, Plant Protection Division, NIAB) for providing Xanthomonas oryzae strains and valuable

\section{REFERENCES}

Adesemoye, A. O., Torbert, H. A., and Kloepper, J. W. (2009). Plant growthpromoting rhizobacteria allow reduced application rates of chemical fertilizers. Microb. Ecol. 58, 921-929. doi: 10.1007/s00248-009-9531-y

Arshad, H. M. I., Naureen, S., Saleem, K., Ali, S., Jabeen, T., and Babar, M. M. (2015). Morphological and biochemical characterization of Xanthomonas oryzae pv. oryzae isolates collected from Punjab during 2013. Adv. Life Sci. 3, 125-130. Available online at: http://www.als- journal.com/235-15/

Audenaert, K., Pattery, T., Cornelis, P., and Höfte, M. (2002). Induction of systemic resistance to Botrytis cinerea in tomato by Pseudomonas aeruginosa 7NSK2: role of salicylic acid, pyochelin, and pyocyanin. Mol. Plant-Microbe Interact. 15, 1147-1156. doi: 10.1094/MPMI.2002.15.11.1147

Ausubel, F. M., Brent, R., Kingston, R. E., Moore, D. D., Seidman, J. G., Smith, J. A., et al. (1992). Current Protocols in Molecular Biology, Vol. 1. New York, NY: Greene Publishing Association; Wiley-Interscience.

Bardin, M., Ajouz, S., Comby, M., Lopez-Ferber, M., Graillot, B., Siegwart, M., et al. (2015). Is the efficacy of biological control against plant diseases likely to be more durable than that of chemical pesticides? Front. Plant Sci. 6:566. doi: $10.3389 /$ fpls.2015.00566

Beneduzi, A., Adriana, A., and Luciane, M. P. P. (2012). Plant growth-promoting rhizobacteria (PGPR): their potential as antagonists and biocontrol agents. Gen. Mol. Biol. 35, 1044-1051. doi: 10.1590/S1415-47572012000600020

Benkeblia, N. (2000). Phenylalanine ammonia-lyase, peroxidase, pyruvic acid and total phenolics variations in onion bulbs during long-term storage. LWT-Food Sci. Technol. 33, 112-116. doi: 10.1006/fstl.1999.0624

Berg, G., Grube, M., Schloter, M., and Smalla, K. (2014). Unraveling the plant microbiome: looking back and future perspectives. Front. Microbiol. 5:148. doi: $10.3389 /$ fmicb. 2014.00148

Bilal, R., Rasul, G., Arshad, M., and Malik, K. A. (1993). Attachment, colonization and proliferation of Azospirillum brasilense and Enterobacter spp. on root surfaces of grasses. World J. Microbiol. Biotechnol. 9, 63-69. doi: $10.1007 /$ BF00656519

Bonaldi, M., Chen, X., Kunova, A., Pizzatti, C., Saracchi, M., and Cortesi, P. (2015). Colonization of lettuce rhizosphere and roots by tagged Streptomyces. Front. Microbiol. 6:25. doi: 10.3389/fmicb.2015.00025

Boukaew, S., Chanasirin, K., and Poonsuk, P. (2013). Potential for the integration ofbiological and chemical control of sheath blight disease caused by Rhizoctonia solani on rice. World J. Microbiol. Biotechnol. 10, 1885-1893. doi: 10.1007/s11274-013-1353-x

Brien, M. O., and Colwall, R. R. (1987). A rapid test for chitinase activity that uses 4-methyl umbelliferyl N-acetyl-beta D-Glucosamine. Appl. Environ. Microbiol. $53,1718-1720$.

Brimecombe, M. J., Leij, D. F. A., and Lynch, J. M. (2001). "The effect of root exudates on rhizosphere microbial populations," in The Rhizosphere, eds R. Pinto, Z. Varanini, and P. Nannipierei (New York, NY: Marcel Dekker), 95-141.

Budzikiewicz, H., and Kesselmeier, J. (1979). Identification of saponins as structural building units in isolated prolamellar bodies from etioplasts of Avena sativa L. Z. Pflanzenphysiol. 91, 333-344. doi: 10.1016/S0044-328X(79)80045-8

Cataldi, T. R., Giuliana, B., and Salvatore, A. (2009). Accurate mass analysis of Nacyl-homoserine-lactones and cognate lactone-opened compounds in bacterial practical guidance. Thanks are due to Mr. Tariq Shah and Mr. M. Sarwar (Technical Assistant, NIBGE) for their assistance.

\section{SUPPLEMENTARY MATERIAL}

The Supplementary Material for this article can be found online at: http://journal.frontiersin.org/article/10.3389/fmicb. 2017.01895/full\#supplementary-material isolates of Pseudomonas aeruginosa PAO1 by LC-ESI-LTQ-FTICR-MS. J. Mass Spectrom. 44, 182-192. doi: 10.1002/jms.1479

Chithrashree, Udayashankar, A. C., Chandra, N. S., Reddy, M. S., and Srinivas, C. (2011). Plant growth-promoting rhizobacteria mediate induced systemic resistance in rice against bacterial leaf blight caused by Xanthomonas oryzae pv. oryzae. Biol. Control 59, 114-122. doi: 10.1016/j.biocontrol.2011.06.010

Chong, H., and Li, Q. (2017). Microbial production of rhamnolipids: opportunities, challenges and strategies. Microb. Cell Fact. 16, 137. doi: 10.1186/s12934-017-0753-2

Combes, M. E., Pothier, J. F., Moenne-Loccoz, Y., and Prigent-Combaret, C. (2011). The Pseudomonas secondary metabolite 2, 4-diacetylphloroglucinol is a signal inducing rhizoplane expression of Azospirillum genes involved in plant-growth promotion. Mol. Plant Microbe Int. 24, 271-284.doi: 10.1094/MPMI-07-10-0148

Couillerot, O., Prigent-Combaret, C., Caballero-Mellado, J., and MoenneLoccoz, Y. (2009). Pseudomonas fluorescens and closely-related fluorescent pseudomonads as biocontrol agents of soil-borne phytopathogens. Lett. Appl. Microbiol. 48, 505-512. doi: 10.1111/j.1472-765X.2009.02566.x

Denizci, D., Kazan, E. C. A., and Erarslan, A. A. (2004). Newly isolated Bacillus clausii GMBAE42, an alkaline protease producer capable to grow under highly-alkaline conditions. J. Appl. Microbiol. 96, 320-327. doi: $10.1046 / j .1365-2672.2003 .02153 . x$

Desjardins, A. E., Manandhar, H. K., Plattner, R. D., Manandhar, G. G., Poling, S. M., and Maragos, C. M. (2000). Fusarium species from Nepalese rice and production of mycotoxins and gibberellic acid by selected species. Appl. Environ. Microbiol. 66, 1020-1025. doi: 10.1128/AEM.66.3.1020-1025.2000

Devi, K. K., and Kothamasi, D. (2009). Pseudomonas fluorescens CHA0 can kill subterranean termite Odontotermes obesus by inhibiting cytochrome $\mathrm{c}$ oxidase of the termite respiratory chain. FEMS Microbiol. Lett. 300, 195-200. doi: 10.1111/j.1574-6968.2009.01782.x

Deziel, E., Lepine, F., Milot, S., He, J., Mindrinos, M. N., Tompkins, R. G., et al. (2004). Analysis of Pseudomonas aeruginosa 4-hydroxy-2alkylquinolines (HAQs) reveals a role for 4-hydroxy-2-heptylquinoline in cell-to-cell communication. Proc. Natl. Acad. Sci. U.S.A. 101, 1339-1344. doi: 10.1073/pnas.0307694100

Dobereiner, J., and Baldani, D. L. V. (1997). Selective infection of maize roots by streptomycin resistant Azospirillun lipoferum and other bacteria. Can. J. Microbiol. 25, 1264-1269. doi: 10.1139/m79-199

Duncan, D. B. (1995). Multiple range and multiple F. tests. Biometrics 11, 1-42. doi: $10.2307 / 3001478$

Falcao, L. L., Silva-Werneck, J. O., Vilarinho, B. R., da Silva, J. P., Pomella, A. W. V. and Marcellino, L. H. (2014). Antimicrobial and plant growth-promoting properties of the cacao endophyte Bacillus subtilis ALB629. J. Appl. Microbiol. 116, 1584-1592. doi: 10.1111/jam.12485

Fang, R., Lin, J., Yao, S., Wang, Y., Wang, J., Zhou, C., et al. (2013). Promotion of plant growth, biological control and induced systemic resistance in maize by Pseudomonas aurantiaca JD37. Ann. Microbiol. 63, 1177-1185. doi: 10.1007/s13213-012-0576-7

Gandhi, P. M., Narayanan, K. B., Naik, P. R., and Sakthivel, N. (2009). Characterization of Chryseobacterium aquaticum strain PUPC1 producing a novel antifungal protease from rice rhizosphere soil. J. Microbiol. Biotechnol. 19, 99-107. doi: 10.4014/jmb.0803.173 
Garcia, S. D. G., Lorza, A. R., and Pelaez, C. A. (2014). Antimicrobial activity of extracellular metabolites from antagonistic bacteria isolated from potato (Solanum phureja) crops. Summa Phytopathol. 40, 212-220. doi: 10.1590/0100-5405/1953

George, M. L., Bustamam, M., Cruz, W. T., Leach, J. E., and Nelson, R. J. (1997). Movement of Xanthomonas oryzae pv. oryzae in southeast Asia detected using PCR-based DNA fingerprinting. Phytopathology 87, 302-309. doi: 10.1094/PHYTO.1997.87.3.302

Gnanamanickam, S. S. (ed.). (2009). "An overview of progress in biological control," in Biological Control of Rice Diseases, Vol. 8 (Dordrecht: Springer), 43-51. doi: 10.1007/978-90-481-2465-7_3

Gould, W. D., Hagedron, C., Bardinelii, T. R., and Zablotowicz, R. M. (1985). New selective media for enumeration and recovery of fluorescent pseudomonads from various habitats. Appl. Environ. Microbiol. 49, 28-32.

Grosso-Becerra, M.-V., Gonzalez-Valdez, A., Granados-Martinez, M.-J., Morales, E., Servin-Gonzalez, L., Mendez, J.-L., et al. (2016). Pseudomonas aeruginosa ATCC 9027 is a non-virulent strain suitable for monorhamnolipids production. Appl. Microbiol. Biotechnol. 100, 9995-10004. doi: 10.1007/s00253-016-7789-9

Hammerschmidt, R., Nuckles, E. M., and Kuc, J. (1982). Association of enhanced peroxidase activity with induced systemic resistance of cucumber to Colletotrichum lagenarium. Physiol. Plant Pathol. 20, 73-82. doi: 10.1016/0048-4059(82)90025-X

Hardy, R. W., Holsten, R. D., Jackson, E. K., and Burns, R. C. (1968). The acetyleneethylene assay for N2 fixation: laboratory and field evaluation. Plant Physiol. 43, 1185-1207. doi: 10.1104/pp.43.8.1185

Heeb, S., Matthew, P. F., Siri, R. C., Stephen, P. D., Paul, W., and Miguel, C. (2011). uinolones: from antibiotics to autoinducers. FEMS Microbiol. Rev. 35, 247-274. doi: 10.1111/j.1574-6976.2010.00247.x

Helene, C., Wagner, B., Patrick, F., and Marc, O. (2011). "Bacillus-based biological control of plant diseases, pesticides in the modern world," in Pesticides Use and Management, ed M. Stoytcheva (Rijeka: InTech), 273-302.

Hewitt, W., and Vincent, S. (1989). Theory and Application of Microbiological Assay. San Diego, CA: Academic Press.

Imran, A., Mirza, M., Shah, T. M., Malik, K. A., and Hafeez, F. Y. (2015). Differential response of kabuli and desi chickpea genotypes towards inoculation with PGPR in different soils. Front. Microbiol. 6:859. doi: $10.3389 /$ fmicb.2015.00859

Jain, R., and Pandey, A. (2016). A phenazine-1-carboxylic acid producing polyextremophilic Pseudomonas chlororaphis (MCC2693) strain, isolated from mountain ecosystem, possesses biocontrol and plant growth promotion abilities. Microbiol. Res. 190, 63-71. doi: 10.1016/j.micres.2016.04.017

Jayaseelan, S., Ramaswamy, D., and Dharmaraj, S. (2014). Pyocyanin: production, applications, challenges and new insights. World J. Microbiol. Biotechnol. 30, 1159-1168. doi: 10.1007/s11274-013-1552-5

Ji, G.-H., Lan-Fang, W., Yue-Qiu, H., Ya-Peng, W., and Xue-Hui, B. (2008). Biological control of rice bacterial blight by Lysobacter antibioticus strain 13-1. Biol. Control 45, 288-296. doi: 10.1016/j.biocontrol.2008.01.004

Kauffman, H. E., Reddy, A. P. K., Hsieh, S. P. Y., and Merca, S. D. (1973). An improved technique for evaluating resistance of rice varieties to Xanthomonas oryzae. Plant Dis. Rep. 57, 537-541.

Khare, E., and Arora, N. K. (2010). Effect of indole-3-acetic acid (IAA) produced by Pseudomonas aeruginosa in suppression of charcoal rot disease of chickpea. Curr. Microbiol. 61, 64-68. doi: 10.1007/s00284-009-9577-6

Khare, E., and Arora, N. K. (2011). Dual activity of pyocyanin from Pseudomonas aeruginosa - antibiotic against phytopathogen and signal molecule for biofilm development by rhizobia. Can. J. Microbiol. 57, 708-713. doi: 10.1139/w11-055

Kidarsa, T. A., Goebel, N. C., Zabriskie, T. M., and Loper, J. E. (2011). Phloroglucinol mediates cross-talk between the pyoluteorin and 2, 4diacetylphloroglucinol biosynthetic pathways in Pseudomonas fluorescens Pf-5. Mol. Microbiol. 81, 395-414. doi: 10.1111/j.1365-2958.2011.07697.x

King, E., Ward, M. K., and Raney, D. E. (1954). Two simple media for the demonstration of pyocyanin and fluorescin. J. Lab. Clin. Med. 44, 301-307.

Kumar, A., Prakash, A., and Johri, B. N. (2011). "Bacillus as PGPR in crop ecosystem," in Bacteria in Agrobiology: Crop Ecosystems, ed D. K. Maheshwari (Berlin; Heidelberg: Springer), 37-59.

Kumar, P., Dubey, R., C., and Maheshwari, D, K. (2012). Bacillus strains isolated from rhizosphere showed plant growth promoting and antagonistic activity against phytopathogens. Microbiol. Res. 167, 493-499. doi: 10.1016/j.micres.2012.05.002

Kumar, R. S., Ayyadurai, N., Pandiaraja, P., Reddy, A. V., Venkateswarlu, Y., Prakash, O., et al. (2005). Characterization of antifungal metabolite produced by a new strain Pseudomonas aeruginosa PUPa3 that exhibits broad-spectrum antifungal activity and biofertilizing traits. J. Appl. Microbiol. 98, 145-154. doi: 10.1111/j.1365-2672.2004. 02435.x

Lepine, F., Milot, S., Deziel, E., He, J., and Rahme, L. G. (2004). Electrospray/ mass spectrometric identification and analysis of 4-hydroxy-2-alkylquinolines (HAQs) produced by Pseudomonas aeruginosa. J. Am. Soc. Mass Spectrom. 15, 862-869. doi: 10.1016/j.jasms.2004.02.012

Li, Q., Jiang, Y., Ning, P., Zheng, L., Huang, J., Li, G., et al. (2011). Suppression of Magnaporthe oryzae by culture filtrates of Streptomyces globisporus JK-1. Biol. Control 58, 139-148. doi: 10.1016/j.biocontrol.2011. 04.013

Liang, J., Tao, X. R., Hao, Z. N., Wang, L. P., and Zhang, X. (2011). Induction of resistance in cucumber against seedling damping-off by plant growthpromoting rhizobacteria (PGPR) Bacillus megaterium strain L8. Afr. J. Biotechnol. 10, 6920-6927. doi: 10.5897/AJB11.260

Lork, H. (1948). Production of hydrocyanic acid by bacteria. Physiol. Plant. 1, 142-146. doi: 10.1111/j.1399-3054.1948.tb07118.x

MacManus, P. S., Stockwell, V. O., Sundin, G. W., and Jones, A. L. (2002). Antibiotic use in plant agriculture. Ann. Rev. Phytopathol. 40, 443-465. doi: 10.1146/annurev.phyto.40.120301.093927

Maddison, W. P., and Maddison, D. R. (1999). MacClade- Analysis of Phylogeny and Character Evolution-Version 3. Sunderland, MA: Sinauer Associates.

Marten, P., Smalla, K., and Berg, G. (2000). Genotypic and phenotypic differentiation of an antifungal biocontrol strain belonging to Bacillus subtilis. J. Appl. Microbiol. 89, 463-471. doi: 10.1046/j.1365-2672.2000. 01136.x

Mehnaz, S., Saleem, R. S. , Yameen, B., Pianet, I., Schnakenburg, G., Pietraszkiewicz, H., et al. (2013). Lahorenoic acids A-C, ortho-dialkylsubstituted aromatic acids from the biocontrol strain Pseudomonas aurantiaca PB-St2. J. Nat. Prod. 76, 135-141. doi: 10.1021/np 3005166

Mew, T. W., and Majid, A. (1977). Bacterial blight of rice in Pakistan. IRRN 2:5.

Mirza, B. S., Welsh, A., Rasul, G., Rieder, J. P., Paschke, M. W., and Hahn, D. (2009). Diversity of Frankia populations in root nodules of different host plant species revealed by nifH gene sequence analysis. Microb. Ecol. 58, 384-393. doi: 10.1007/s00248-009-9513-0

Montano, P. F., Alias-Villegas, C., Bellogin, R. A., del-Cerro, P., Espuny, M. R., Jimenez-Guerrero, I., et al. (2014). Plant growth promotion in cereal and leguminous agricultural important plants: from microorganism capacities to crop production. Microbiol. Res. 169, 325-336. doi: 10.1016/j.micres.2013.09.011

Mousivand, M., Jouzani, G. S., Monazah, M., and Kowsari, M. (2012). Characterization andantagonistic potential of some native biofilm forming and surfactant producing Bacillus subtilis strains against six pathotypes of Rhizoctonia solani. J. Plant Pathol. 94, 171-180. doi: 10.4454/jpp.v94i1.017

Murphy, J., and Riley, J. P. (1962). A modified single method for the determination of phosphate in natural waters. Anal. Chim. Acta 27, 31-36. doi: 10.1016/S0003-2670(00)88444-5

Nain, M. L., Yadav, R. C., and Saxena, J. (2012). Characterization of Multifaceted Bacillus spp. RM-2 for its use as plant growth promoting bioinoculant for crops grown in semiarid deserts. Appl. Soil Ecol. 59,124-135. doi: 10.1016/j.apsoil.2011.08.001

Naureen, Z., Rehman, N. U., Hussain, H., Hussain, J., Gilani, S. A., Al Housni, S. K., et al. (2017). Exploring the potentials of Lysinibacillus sphaericus ZA9 for plant growth promotion and biocontrol activities against phytopathogenic fungi. Front. Microbiol. 8:1477. doi: 10.3389/fmicb.2017. 01477

Neuenhaus, W., Budzikiewicz, H., Korth, H., and Pulverer, G. (1979). Bacterial constituents, III 3-Alkyl-tetrahydroquinoline derivatives from Pseudomonas. J. Chem. Sci. 34, 313-315.

Nino-Liu, D., Ronald, P., and Bogdanove, A. (2006). Xanthomonas oryzae pathovars: model pathogens of a model crop. Mol. Plant Pathol. 7, 303-324. doi: $10.1111 /$ j.1364-3703.2006.00344.x 
Norris, J. R., and Ribbons, D. W. (1970). Methods in Microbiology, Vol, 3A. Available online at: http://public.eblib.com/choice/publicfullrecord.aspx?p= 413709

Ortori, C. A., Dubern, J. F., Chhabra, S. R., Camara, M., Hardie, K., Williams, P., et al. (2011). Simultaneous quantitative profiling of N-acyl-Lhomoserine lactone and 2-alkyl-4 $(1 \mathrm{H})$-quinolone families of quorum-sensing signaling molecules using LC-MS/MS. Anal. Bioanal. Chem. 399, 839-850. doi: $10.1007 / \mathrm{s} 00216-010-4341-0$

Ou, S. H. (1985). Rice Diseases. Kew: Commonwealth Mycological Institute.

Penrose, D. M., and Glick, B. R. (2003). Methods for isolating and characterizing ACC deaminase-containing plant growth promoting rhizobacteria. Physiol. Plant. 118, 10-15. doi: 10.1034/j.1399-3054.2003. 00086.x

Perez, L. M., Besoain, X., Reyes, M., Parado, G., and Montealegre, J. R. (2002). The expression of extracellular fungal cell wall hydrolytic enzymes in different Trichoderma harzianum isolates correlate with their ability to control Pyrenochaeta lycopersici. Biol. Res. 35, 401-410. doi: 10.4067/S0716-97602002000300014

Petatan-Sagahon, I., Anducho-Reyes, M. A., Silva-Rojas, H. V., Arana-Cuenca, A., Tellez-Jurado, A., Cardenas-Alvarez, I. O., et al. (2011). Isolation of bacteria with antifungal activity against the phytopathogenic fungi Stenocarpella maydis and Stenocarpella macrospora. Int. J. Mol. Sci. 12, 5522-5537. doi: $10.3390 /$ ijms 12095522

Price-Whelan, A., Dietrich, L. E., and Newman, D. K. (2006). Rethinking secondary metabolism: physiological roles for phenazine antibiotics. Nat. Chem. Biol. 2, 71-78. doi: 10.1038/nchembio764

Qing, F., Shiping, T., Haibo, L., and Yong, X. (2002). Production of $\beta-1,3-$ glucanase and chitinase of two biocontrol agents and their possible modes of action. Chin. Sci. Bull. 47, 292-296. doi: 10.1360/02tb9070

Rachid, D., and Bensoltane, A. (2005). Effect of iron and growth inhibitors on siderophores production by Pseudomonas fluorescence. Afr. J. Biotechnol. 4, 697-702. doi: 10.5897/AJB2005.000-3129

Radhapriya, P., Ramachandran, A., Anandham, R., and Mahalingam, S. (2015). Pseudomonas aeruginosa RRALC3 enhances the biomass, nutrient and carbon contents of Pongamia pinnata seedlings in degraded forest soil. PLoS ONE 10:e0139881. doi: 10.1371/journal.pone.0139881

Reddy, K. S., Khan, M. Y., Archana, K., Reddy, M. G., and Hameeda, B. (2016). Utilization of mango kernel oil for the rhamnolipid production by Pseudomonas aeruginosa DR1 towards its application as biocontrol agent. Bioresour. Technol. 221, 291-299. doi: 10.1016/j.biortech.2016. 09.041

Saikia, R., Yadav, M., Varghese, S., Singh, B. P., Gogoi, D. K., and Kumar, R. (2006). Role of riboflavin in induced resistance against Fusarium wilt and charcoal rot diseases of chickpea. Plant Pathol. J. 24, 339-347. doi: 10.5423/PPJ.2006.22.4.339

Schwyn, B., and Neilands, J. B. (1987). Universal chemical assay for detection and determination of siderophores. Anal. Biochem. 160, 40-47. doi: 10.1016/0003-2697(87)90612-9

Shah, S. M. A., Hidayat, U. R., Abassi, F. M., Rafi, M. A. A., and Khan, I. A. (2009). Resistance characterization of wild relatives of rice in response to bacterial blight. Pak. J. Bot. 41, 917-925. Available online at: http://www.pakbs.org/pjbot/ PDFs/41(2)/PJB41(2)917.pdf

Shanti, M. L., Shenoy, V. V., Devi, G. L., Kumar, V. M., Premalatha, P., Kumar, G. N., et al. (2010). Marker-assisted breeding for resistance to bacterial leaf blight in popular cultivar and parental lines of hybrid rice. J. Plant Pathol. 92, 495-501. doi: 10.4454/jpp.v92i2.194

Simonetti, E., Carmona, M. A., Scandiani, M. M., Garci, A. F., Luque, A. G., Correa, O. S., et al. (2012). Evaluation of indigenous bacterial strains for biocontrol of the frogeye leaf spot of soya bean caused by Cercosporasojina. Lett. Appl. Microb. 55, 170-173. doi: 10.1111/j.1472-765X.2012.03266.x

Singh, R. P., and Jha, P. N. (2016). Alleviation of salinity-induced damage on wheat plant by an ACC deaminase-producing halophilic bacterium Serratia sp. SL- 12 isolated from a salt lake. Symbiosis. 69, 101-111. doi: 10.1007/s13199-016-0387-x

Singh, S., Chand, S., Singh, N. K., and Sharma, T. R. (2015). Genome-Wide Distribution, Organization and functional characterization of disease resistance and defence response genes across rice species. PLoS ONE 10:e0125964. doi: 10.1371/journal.pone.0125964
Soberon-Chavez, G., Lepine, F., and Deziel. E. (2005). Production of rhamnolipids by Pseudomonas aeruginosa. Appl. Microb. Biotechnol. 68, 718-725. doi: 10.1007/s00253-005-0150-3

Somasegaran, P., and Hoben, H. J. (1994). Handbook for Rhizobia Methods in Legume-Rhizobium Technology. New York, NY; Heidelberg: Springer. doi: 10.1007/978-1-4613-8375-8

Spence, C. A., Raman, V., Donofrio, N. M., and Bais, H. P. (2014). Global gene expression in rice blast pathogen Magnaporthe oryzae treated with a natural rice soil isolate. Planta 239, 171-185. doi: 10.1007/s00425-013-1974-1

Sulochana, M. B., Jayachandra, S. Y., Kumar, S. A., Parameshwar, A. B., Reddy, K. M., and Dayan, A. (2014). Siderophore as a potential plant growth-promoting agent produced by Pseudomonas aeruginosa JAS-25. Appl. Biochem. Biotechnol. 174, 297-308. doi: 10.1007/s12010-014-1039-3

Susana, C. S., Herschkovitz, Y., Okon, Y., and Edouard, J. (2007). Effects of inoculation with plant growth-promoting rhizobacteria on resident rhizosphere microorganisms. FEMS Microbiol. Lett. 276, 1-11. doi: 10.1111/j.1574-6968.2007.00878.x

Tan, Z. Y., Xu, X. D., Wang, E. T., Gao, J. L., Martinez-Romero, E., and Chen, W. X. (1997). Phylogenetic and genetic relationships of Mesorhizobium tianshanense and related rhizobia. Int. J. Syst. Bacteriol. 47, 874-879. doi: 10.1099/00207713-47-3-874

Tariq, M., Hameed, S., Malik, K. A., and Hafeez, F. Y. (2007). Plant root associated bacteria for zinc mobilization in rice. Pak. J. Bot. 39, 245-253. Available online at: http://www.pakbs.org/pjbot/PDFs/39(1)/PJB39(1)245.pdf

Thompson, J. D., Gibson, T. J., Plewniak, F., Jeanmougin, F., and Higgins, D. G. (1997). The CLUSTAL_X windows interface: flexible strategies for multiple sequence alignment aided by quality analysis tools. Nucleic Acids Res. 25, 4876-4882. doi: $10.1093 /$ nar/25.24.4876

Tien, T. M., Gaskins, M. H., and Hubbell, D. H. (1979). Plant growth substances produced by Azospirillum brasilense and their effect on the growth of pearl millet (Pennisetum americanum L.). Appl. Environ. Microbiol. 37, 1016-1024

Trivedi, P., Pandey, A., and Palni, L. M. (2008). In vitro evaluation of antagonistic properties of Pseudomonas corrugata. Microbiol. Res. 163, 329-336. doi: 10.1016/j.micres.2006.06.007

Valverde, A., Velazquez, E., Fernandez-Santos, F., Vizcaino, N., Rivas, R., Mateos, P. F., et al. (2005). Phyllobacterium trifolii sp. nov., nodulating Trifolium and Lupinus in Spanish soils. Int. J. Syst. Evol. Microbiol. 55, 1985-1989. doi: 10.1099/ijs.0.63551-0

Vassilev, N., Vassileva, M., and Nikolaeva, I. (2006). Simultaneous P-solubilizing and biocontrol activity of microorganisms: potentials and future trends. Appl. Microbiol. Biotechnol. 71, 137-144. doi: 10.1007/s00253-006-0380-z

Velusamy, P., Immanuel, J. E., Gnanamanickam, S. S., and Thomashow, L. (2006). Biological control of rice bacterial blight by plant-associated bacteria producing 2,4-diacetylphloroglucinol. Can. J. Microbiol. 52, 56-65. doi: 10.1139/w05-106

Vial, L., Lepine, F., Milot, S., Groleau, M. C., Dekimpe, V., Woods, D. E., et al. (2008). Burkholderia pseudomallei, B. thailandensis, and B. ambifaria produce 4-hydroxy-2-alkylquinoline analogues with a methyl group at the 3 position that is required for quorum-sensing regulation. J. Bacteriol. 190, 5339-5352. doi: $10.1128 /$ JB. $00400-08$

Vidhyasekaran, P., Kamala, N., Ramanathan, R., Rajappan, K., Paranidharan, V., and Velazhahan, R. (2001). Induction of systemic resistance by Pseudomonas fluorescens Pf1 against Xanthomonas oryzae pv. oryzae in rice leaves. Phytoparasitica 29, 155-166. doi: 10.1007/BF02983959

Vilchez, J. I., Navas, A., Gonzalez-Lopez, J., Arcos, S. C., and Manzanera, M. (2016). Biosafety test for plant growth-promoting bacteria: proposed Environmental and Human Safety Index (EHSI) protocol. Front. Microbiol. 6:1514. doi: 10.3389/fmicb.2015.01514

Vleesschauwer, D. D., Chernin, L., and Hofte, M. M. (2009). Differential effectiveness of Serratia plymuthica IC1270-induced systemic resistance against hemibiotrophic and necrotrophic leaf pathogens in rice. BMC Plant Biol. 9:9. doi: 10.1186/1471-2229-9-9

Wang, J., Quan, C., Wang, X., Zhao, P., and Fan, S. (2011). Extraction, purification and identification of bacterial signal molecules based on $\mathrm{N}$-acyl homoserine lactones. Microb. Biotechnol. 4, 479-490. doi: 10.1111/j.1751-7915.2010.00197.x

Wang, Y., Li, C., Gao, C., Ma, C., and Xu, P. (2014). Genome sequence of the nonpathogenic Pseudomonas aeruginosa strain ATCC 15442. Genome Announc. 2:e00421-14. doi: 10.1128/genomeA.00421-14 
Weisany, W., Sohrabi, Y., Heidari, G., Siosemardeh, A., and Ghassemi, G. K. (2012). Changes in antioxidant enzymes activity and plant performance by salinity stress and zinc application in soybean (Glycine max L.). Plant Omics J. 5, 60-67. Available online at: http://www.pomics.com/sohrabi_5_2_2012_60_ 67.pdf

Weller, D. M. (2007). Pseudomonas biocontrol agents of soil-borne pathogens: looking back over 30 years. Phytopathology 97, 250-256. doi: 10.1094/PHYTO-97-2-0250

Wensing, A., Braun, S. D., Buttner, P., Expert, D., Volksch, B., Ullrich, M. S., et al. (2010). Impact of siderophore production by Pseudomonas syringae pv. syringae $22 \mathrm{~d} / 93$ on epiphytic fitness and biocontrol activity against Pseudomonas syringae pv. glycinea 1a/96. Appl. Environ. Microbiol. 76, 2704-2711. doi: 10.1128/AEM.02979-09

Wimberly, J. E. (1983). Technical Hand Book for the Paddy Rice Postharvest Industry in Developing Countries. Laguna: International Rice Research Institute.

Worthington, C. C. (1988). Worthington Enzyme Manual: Enzymes and Related Biochemicals. Freehold, NJ: Worthington Biochemical Corporation.

Yasmin, S., Hafeez, F. Y., and Rasul, G. (2014). Evaluation of Pseudomonas aeruginosa for biocontrol of cotton seedling disease caused by Fusarium oxyporum. Biocontrol Sci. Technol. 24, 1227-1242. doi: 10.1080/09583157.2014.932754
Yasmin, S., Zaka, A., Zahid, M. A., Imran, A., Yousaf, S., Rasul, G., et al. (2016). Plant growth promotion and suppression of bacterial leaf blight in rice by inoculated bacteria. PLOS ONE 11:e160688. doi: 10.1371/journal.pone. 0160688

Youard, Z. A., Mislin, G. L., Majcherczyk, P. A., Schalk, I. J., and Reimmann, C. (2007). Pseudomonas fluorescens CHA0 produces enantio-pyochelin, the optical antipode of the Pseudomonas aeruginosa siderophore pyochelin. J. Biol. Chem. 282, 35546-35553. doi: 10.1074/jbc.M7070 39200

Conflict of Interest Statement: The authors declare that the research was conducted in the absence of any commercial or financial relationships that could be construed as a potential conflict of interest.

Copyright (c) 2017 Yasmin, Hafeez, Mirza, Rasul, Arshad, Zubair and Iqbal. This is an open-access article distributed under the terms of the Creative Commons Attribution License (CC BY). The use, distribution or reproduction in other forums is permitted, provided the original author(s) or licensor are credited and that the original publication in this journal is cited, in accordance with accepted academic practice. No use, distribution or reproduction is permitted which does not comply with these terms. 